\title{
MR connectomics: a conceptual framework for studying the developing brain
}

\author{
Patric Hagmann $^{1,2}$, Patricia E. Grant ${ }^{3,4,5}$ and Damien A. Fair ${ }^{6}$ \\ ${ }^{1}$ Department of Radiology, Lausanne University Hospital and University of Lausanne (CHUV-UNIL), Lausanne, Switzerland \\ 2 Signal Processing Laboratory 5, Ecole Polytechnique Fédérale de Lausanne (EPFL), Lausanne, Switzerland \\ ${ }^{3}$ Fetal-Neonatal Neuroimaging and Developmental Science Center, Children's Hospital Boston, Boston, MA, USA \\ ${ }^{4}$ Division of Newborn Medicine and Department of Radiology, Children's Hospital Boston, Boston, MA, USA \\ ${ }^{5}$ Athinoula A. Martinos Center for Biomedical Imaging, MGH-Harvard, Boston, MA, USA \\ ${ }^{6}$ Department of Psychiatry, Oregon Health and Science University, Portland, OR, USA
}

\section{Edited by:}

Robert Turner, Max Planck Institute for Human Cognitive and Brain

Sciences, Germany

\section{Reviewed by:}

Kuei Y. Tseng, Rosalind Franklin

University of Medicine and

Science, USA

Thomas R. Knösche, Max Planck

Institute for Human Cognitive and

Brain Sciences, Germany

\section{*Correspondence:}

Patric Hagmann, Department of Radiology, Lausanne University Hospital and University of Lausanne, Rue du Bugnon 46, 1011 Lausanne-CHUV, Switzerland. e-mail: patric.hagmann@epfl.ch
The combination of advanced neuroimaging techniques and major developments in complex network science, have given birth to a new framework for studying the brain: "connectomics." This framework provides the ability to describe and study the brain as a dynamic network and to explore how the coordination and integration of information processing may occur. In recent years this framework has been used to investigate the developing brain and has shed light on many dynamic changes occurring from infancy through adulthood. The aim of this article is to review this work and to discuss what we have learned from it. We will also use this body of work to highlight key technical aspects that are necessary in general for successful connectome analysis using today's advanced neuroimaging techniques. We look to identify current limitations of such approaches, what can be improved, and how these points generalize to other topics in connectome research.

Keywords: connectivity, networks, diffusion MRI, tractography, resting state functional MRI, human brain, development

\section{INTRODUCTION}

The first two decades of life represents a period of developmental change in sensory, motor, and cognitive abilities. One of the ultimate goals of developmental cognitive neuroscience is to link the complex behavioral milestones that occur throughout this time period with the equally intricate functional and structural changes of the underlying neural substrate. Much of the human developmental literature has focused on localizing and classifying the function of individual brain regions and how these regional specializations arise; however, in recent years, buoyed by the methodological improvements of magnetic resonance imaging (MRI), there has been a growing interest and re-emerging emphasis on examining how these specialized neural processes become integrated and how the level of integration changes with development.

The foundation of these new efforts in examining the system organization that supports the selection and coordination of distributed neural processes lies in brain connectivity. There are predominantly three forms of brain connectivity that are likely to facilitate orchestrated information flow-anatomical connectivity, functional connectivity, and the related effective connectivity. Anatomical connectivity as the name suggests, relates to the axonal connections that directly link neural ensembles. Functional connectivity, on the other hand, is defined as "temporal correlations between spatially remote neurophysiological events" (Friston et al., 1993; Lee et al., 2003). While the majority of the work described below will focus on these two phenomena, it should be noted that effective connectivity, which measures causal relations between segregated neural units, is an important (if not ideal) way to examine the nature of integrated processes (Friston, 2002; Stephan, 2004). Unfortunately, methods to measure effective connectivity in humans with todays MR measurements are particularly challenging (Smith et al., 2011).

Until recently the evaluation of structural (axonal) connections between different areas of the brain was only accessible by post-mortem chemical tracing and histological methods. These techniques were able to map to some extent the mesoscopic architecture of white matter connectivity in the primate (Schmahmann and Pandya, 2006), but are limited very local and microscopic connectivity patterns in rodent (e.g., Denk and Horstmann, 2004; Micheva and Smith, 2007; Lichtman et al., 2008). These microscopic techniques are cumbersome, have low throughput and cannot be used in humans. Furthermore, they cannot be used in vivo. Electrophysiological methods such as evoked potentials, Electro-Encephalo-Graphy (EEG) and Magneto-Encephalo-Graphy (MEG) are non-invasive techniques that assess function or functional connectivity between brain areas. They have proven their utility in studying fundamental brain properties in development and pathologic conditions (e.g., Srinivasan, 1999; Varela et al., 2001; Jeong, 2004; Sahin et al., 2009; Stam, 2010; Gonzalez et al., 2011). However, poor spatial localization of these techniques makes it difficult to study functionally related systems. Over the last decade tremendous developments in MRI have occurred, which have allowed us to 
move beyond these aforementioned techniques. Of particular interest to the study developing brain connectivity are advances in diffusion and resting state functional MRI. These techniques have good spatial resolution and are able to study macroscopic and long-range structural and functional connectivity in vivo across development.

\section{IMAGING STRUCTURAL CONNECTIVITY}

Water molecules inside tissues experience random motion due to thermal energy, which is commonly referred to as Brownian motion (Einstein, 1956; Le Bihan, 1995). Diffusion-weighted MRI is sensitive to this Brownian motion because it magnetically labels moving protons. Diffusion-weighted MRI came under the spot light in the medical community in the early 1990s when it was first demonstrated that diffusion-weighted MRI is exquisitely sensitivity to acute stroke (Moseley et al., 1990). A few years later another discovery attracted even more attention to diffusion imaging. Scientists observed that the diffusion coefficient was orientation dependent in white matter (Douek et al., 1991; Basser et al., 1994). These orientational biases reflect underlying axonal coherence at the voxel level and are now used for mapping axonal bundle trajectories (Wedeen, 1996; Conturo et al., 1999; Mori et al., 1999). Over the years, improved MRI hardware and diffusion acquisition schemes as well as tractography algorithms have been developed (Hagmann et al., 2006, 2010a). Today it is possible to acquire in vivo datasets that can be used to map brain structural connectivity by reconstructing thousands of fiber pathways connecting hundreds of gray matter regions in clinically feasible times (Hagmann et al., 2007; Iturria-Medina et al., 2008). This technology has now been utilized in numerous applications and across multiple fields (Nucifora et al., 2007; Johansen-Berg and Rushworth, 2009; Wedeen et al., 2012).

As will be discussed below, the method is not without limitations. For example, diffusion based connectivity does not provide a wholesale account of the connective patterns in the brain. It is restricted to the examination of axonal groups who path remains coherent over large scales. Microscopic information such as the number of axons and g-ratio are difficult if not impossible to ascertain. In addition there is also a lack of specificity with information about the direction of information transfer, synapses and receptors inaccessible. Finally there are some axonal pathways that are difficult to reconstruct even with the best techniques due to small axonal size and/or number, axonal crossings, or sharp angle turns. Nonetheless, our current ability to map whole brain structural connectivity in a relatively short period of time enables us to study global network organizational properties of the brain and their relation to development and pathology. This network perspective has led to the definition of a new concept: the "connectome" (Hagmann, 2005; Sporns et al., 2005). In complete analogy to the word "genome," this new "-ome" emphasizes the notion that the brain is a large and unique complex system: a network made of structural and functional connections (edges) linking specific neural units (nodes).

\section{IMAGING FUNCTIONAL CONNECTIVITY}

The Blood-Oxygen-Level-Dependent (BOLD) signal captured by functional MRI is an indirect measure of local neural activity
(Logothetis and Wandell, 2004). Over the years fMRI has played a tremendously important role in mapping task-induced cognitive functions onto neuroanatomy. More recently a complement to these traditional task-based studies has become popular. These new studies examine intrinsic, temporally correlated lowfrequency BOLD signals in subjects at rest, not performing any task. This technique is most often referred to as resting state functional connectivity MRI ( $\mathrm{rs}-\mathrm{fcMRI}$ ). Biswal and colleagues were the first to report that low frequency resting state BOLD signal fluctuations in the brain were organized into functionally relevant systems (Biswal et al., 1995). While the implications of this work were initially slow to capture the collective attention of the scientific community, the last several years have witnessed an exponential rise in investigations using rs-fcMRI. To date, rsfcMRI has been used to examine systems-level organization of visual (Lowe et al., 1998), auditory (Cordes et al., 2001), motor (Biswal et al., 1995), memory (Hampson et al., 2006), language (Xiang et al., 2010), attention (Fox et al., 2006), and task control systems (Dosenbach et al., 2007). It has been used to study aging (Greicius et al., 2004; Andrews-Hanna et al., 2007), as well as disorders such as schizophrenia (Tononi and Edelman, 2000), autism (Just et al., 2007), Alzheimer's disease (Greicius et al., 2004), Tourette syndrome (Church et al., 2009), and ADHD (Castellanos et al., 2008; Fair et al., 2010b), just to name a few. It has even been increasingly used in animal and rodent models, including nonhuman primates, with results that suggest system organization is at least partly preserved across species (Vincent et al., 2007). Lastly, the technique shows very consistent results across subjects, scanners, and days (Damoiseaux et al., 2006; Shehzad et al., 2009) making it an attractive method for large multicenter studies.

Importantly, and one limitation of the measure (amongst others described below), is that the origin of these low frequency BOLD time series correlations is still largely unknown. There are suggestions that neuronal activity in the gamma and delta frequency spectrum as measured from EEG and MEG are related to these low frequency BOLD oscillations ( $\mathrm{Lu}$ et al., 2007; He and Liu, 2008; Scholvinck et al., 2010). These findings have led to the popular belief that these low frequency BOLD signal oscillations are the envelope of higher frequency evoked field potentials, which are directly related to action potentials of populations of neurons (local field potentials or LFPs). Correlation between two BOLD time series coming from different parts of the brain is a measure of statistical dependence in the neuronal activity of these two populations of neurons. If this dependence is high between two brain regions, these regions are said to be "functionally connected." Significant and high correlations are observed not only between regions directly connected structurally but also between regions that are known to have multi-synaptic connections (Vincent et al., 2007).

\section{THE RELATION BETWEEN STRUCTURAL AND FUNCTIONAL CONNECTIVITY}

If human structural brain networks can be reliably partitioned into tens or hundreds of distinct network modules, then it is expected that these modules will correspond to functionally localized subdivisions of the brain. To support this hypothesis, Johansen-Berg and colleagues have shown that connection-based 
subdivisions of the premotor cortex correspond closely to the subdivisions identified using functional imaging of motor and linguistic tasks in the same individuals (Johansen-Berg et al., 2004). Similar approaches where used to identify structural entities inside the thalamus (Zhang et al., 2008), the inferior frontal cortex (Anwander et al., 2007), the cingulate cortices (Beckmann et al., 2009), and the visual secondary pathways (Hagmann et al., 2008).

Over the last few years several studies have focused on the relationship between resting state functional connectivity and structural connectivity. These studies showed largely convergent results (Koch et al., 2002; Hagmann et al., 2008; Greicius et al., 2009; Honey et al., 2009), indicating that at the regional as well as at the connectome (Hagmann, 2005; Sporns et al., 2005) level, the strength of functional connectivity is positively correlated with the strength of structural connectivity, when direct or indirect structural connectivity is present and measurable. When the latter is not present functional connectivity is generally more variable but still can be strong (Honey et al., 2009). There is further evidence that there is significant correlation between structural white matter coherence and EEG functional connectivity in healthy controls and patients suffering of amnesic mild cognitive impairment (Teipel et al., 2009).

To even further probe the structure-function relation, a number of computational experiments have combined inter-regional connectivity data with intra-regional circuit and cellular properties to produce large-scale models of cortical (Honey et al., 2007, 2009; Ghosh et al., 2008; Knock et al., 2009) and cortico-thalamic function (Izhikevich and Edelman, 2008) (Figure 1). These models have shown a strong predictability of the low frequency functional activity from the model, which supports the concept that functional activity is largely shaped by the underlying physical wiring (at least in adult populations).

\section{BRAIN DEVELOPMENT \\ DEVELOPMENT OF STRUCTURAL CONNECTIVITY}

The development of structural connectivity is a complex process that is not fully understood. The rich diversity of structural brain connectivity beyond that determined by genetics is thought to be mediated by activity-dependent stabilization of developing synapses and selective elimination (Changeux and Danchin, 1976). Therefore, activity mediated self-organization has come to be considered a fundamental characteristic of brain development (Grossberg, 1980; Changeux et al., 1984; Edelman and Finkel, 1985; Montague et al., 1991; von der Malsburg, 1995; Johnson, 1997; Werner, 2007). The cellular and molecular events that govern the process of developing cortical connectivity is complex and beyond the scope of this paper. However, it is widely accepted that activity-independent mechanisms dominate during the early phases of cortical connectivity development with later refinement governed by activity dependent mechanisms (Price et al., 2006). A basic outline of the timeline for the development of major connections is provided below to help provide a framework for understanding this complex process.

Axonal afferent connections first start to appear around the 8th post conceptual week (PCW) and continue to form until the neonatal period (Muller and O'Rahilly, 2006; Vasung et al., 2011a,b). After thalamo-cortical and basal forebrain axonal afferents emerge around $8 \mathrm{PCW}$, they continue to extend toward the cortical plate $(\mathrm{CP})$ and undergo a waiting period in the subplate beginning around 13-14 PCW. After 23 PCW they penetrate the CP guided by subplate neurons. The development of cortical efferents is less well characterized but is related to the cortical layer of destination in that neurons destined for different layers will begin to develop different layer specific connections (Lotto et al., 1999; Price et al., 2006). Corpus callosum axons develop a few weeks after the thalmo-cortical axons and are evident by 11 PCW (Vasung et al., 2011a,b). Projection axons from the motor cortex are evident as early as 24 PCW (Eyre et al., 2000). Long and local cortico-cortical connections are difficult to detect by standard immunochemical or histological techniques but diffusion imaging studies detect tracts consistent with many long association systems as early as 17 PCW (Vasung et al., 2011 a,b; Huang et al., 2006; Takahashi et al., 2011b). Specification of cortical areas occurs through afferents, primarily thalamocortical, and is followed by a phase of exhuberent connectivity which is further refined by selective pruning (Innocenti, 1995). Recent studies suggest that refinement of exuberant connectivity may play a more important role in infragranular feedback circuits than supraganular feed-forward circuits (Price et al., 2006).

Although the vast majority of our knowledge about developing connectivity comes from histological and immunochemical studies of specimens, as noted above, diffusion imaging of fixed human fetal specimens is beginning to have a significant impact on our understanding of developing human brain connectivity. Unlike the histological and immunochemical studies where only a few slices or small regions are studied, MRI tractography allows a whole brain 3D evaluation of tissue coherence providing information on regional organization changes as early as 11 PCW (Vasung et al., 2011a,b). Radial and tangential migration routes can be identified as well as emerging long and short-range association systems (Figure 2) (Huang et al., 2006; Vasung et al., 2011a,b; Takahashi et al., 2011b, 2012). Potential for in vivo observation of early fetal developing connectivity exists as currently early reports of in vivo fetal tractography exist (Kasprian et al., 2008).

From the neonatal period onwards, analysis of in vivo diffusion acquisitions predominates over ex vivo techniques. With axonal connections in place, white matter changes reported from infancy to approximately 2 year of age are predominantly a reflection of developing myelination and axonal loss due to pruning. Synaptic density peaks around 1 year of age with rapid process elimination during preschool years (Huttenlocher, 1984). Tractography studies in newborns detect all the major pathways (Dubois et al., 2006; Liu et al., 2010). From birth to adolescence, diffusivity (ADC) decreases and fractional anisotropy (FA) increases (Dubois et al., 2006; Huppi and Dubois, 2006; Mukherjee and McKinstry, 2006; Cascio et al., 2007; Eluvathingal et al., 2007; Hagmann et al., 2010b; Liu et al., 2010). Current studies do not capture the exuberant number of axonal branches that regress during early development and in fact typically show more tracts with increasing age, which likely is an artifact of tractography (see below). However, these studies do detect asynchronous and asymmetric development 


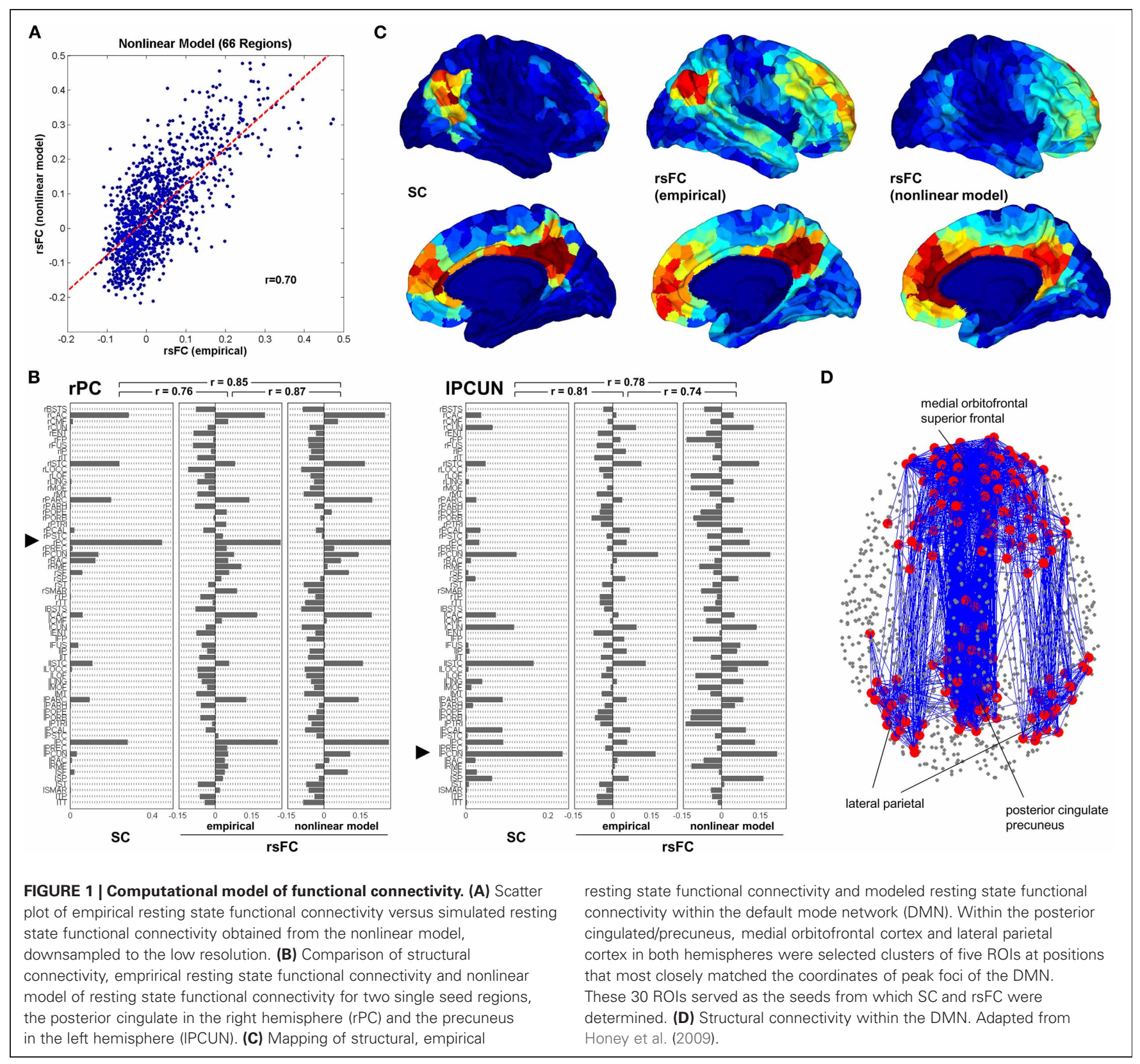

of white matter tracts. The decreasing diffusivity and increasing FA is thought to be due to increasing myelin and myelin maturation.

From childhood to early adult, changes in diffusion measures of connectivity should be largely due to myelin modulation as the measure is most sensitive to large-fiber bundles, which are intact early in development Importantly, this measurement is likely providing additional information not always considered by traditional (i.e., non-MRI) structural connectivity techniques and theories which typically focus on the patterns of connectivity. Temporal information transfer is not only governed by the pattern of connectivity, but also axonal diameter, axonal length, and myelination (Innocenti, 1995; Chen et al., 2002; Butefisch, 2004). In fact, surrogate markers such as regional diffusivity has been shown to drive increased structural connection efficiency, contribute to increasing small worldedness and improved matching of structural and functional connectivity from 18 months to 18 years (Hagmann et al., 2010b).

Similar to the cerebral and thalamic connections, the pontocerebellar connections undergo a phase of exuberant connectivity and elimination (Kalinovsky et al., 2011). Although tractography studies of mature cerebellar connections exist (Granziera et al., 2009), little data is currently available on developing cerebellar structural connectivity using MRI tractography (Saksena et al., 2008a,b; Aeby et al., 2009). A number of groups and currently studying this process given the profound impact cerebellar development has on cognitive development. 


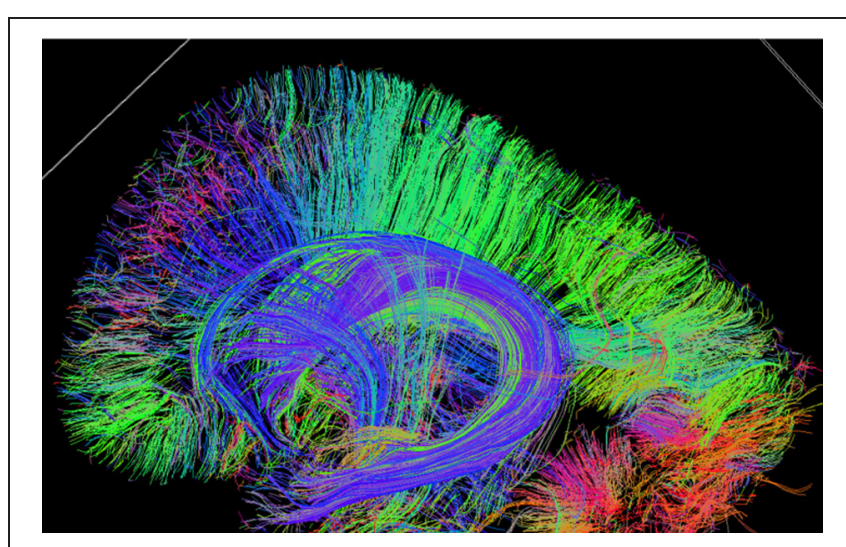

FIGURE 2 | Sagittal tractography image of an 18 week gestational age fetal pathology specimen shows highly radial coherence of the cerebral mantel consistent with radial migration [courtesy of Emi Takahashi (Takahashi et al., 2011a)].

\section{FUNCTIONAL CONNECTIVITY ACROSS DEVELOPMENT}

As early as 1875 spontaneous synchronized neural activity has been used to study various aspects of adult brain organization (Caton, 1875; Berger, 1929, 1933; Swartz and Goldensohn, 1998). However, despite the passing of over 130 years since its inception, there has been little work detailing its role in developmental phenomena occurring after birth.

To date, likely the most recognized function of spontaneous correlated activity in postnatal development is its influence on the maturation of ocular dominance columns (ODC). While there have been other prominent views of how ODC develop (Sur and Leamey, 2001; Katz and Crowley, 2002; Luo and O'Leary, 2005; Price et al., 2006), the most prominent account proposes that spontaneous synchronized neural events play a role. This work has shown that the presence of retinal inputs are not required for the segregation of layer IV projections into well-delineated columns. Rather, activity in the form of intrinsic burst of correlated activity from the lateral geniculate nucleus (LGN) can account for ODC formation (Crowley and Katz, 1999; Sur and Leamey, 2001; Katz and Crowley, 2002). Indeed, the eye specific layers of the LGN itself are also likely formed prenatally, at least in part, secondary to spontaneous neural activity (Sur and Leamey, 2001).

While the formation of ODC occurs fairly early after birth, until recently little work has been done concerning the development and role of intrinsic correlated activity in later postnatal years. As such, there is much to explore regarding functional connectivity and its relation to brain development.

The earliest work to examine brain systems in children with rsfcMRI came from Kiviniemi et al. (2000). In this study the authors evaluated resting-state baseline fluctuations in 12 children anesthetized with thiopental. The authors found bilateral organized correlated activity in the striate and extrastriate visual cortex in these children. While the work was limited to the visual cortex it was important, as it showed that low-frequency, correlated intrinsic activity could be measured via BOLD fMRI in populations as young as 3 months of age. Several years later it was recognized that similar phenomena could be observed during sleep as well (Redcay et al., 2007).

The realization that functional brain organization could be measured via rs-fcMRI in children and infants at rest, during sleep, or under anesthesia in the absence of experimental manipulation, quickly led to a series of reports investigating the brain's maturing functional architecture. The first study to examine large-scale systems using rs-fcMRI in sleeping infants was done by Fransson et al. (2007). In this report Fransson and colleagues used independent component analysis to examine functional networks in sedated premature infants scanned at term equivalent. The study expanded on early findings (Kiviniemi et al., 2000; Redcay et al., 2007) and showed rs-fcMRI delineated the visual cortex along with somatomotor and auditory systems. They also showed two other segregated components: one consisting of medial and lateral parietal cortex, and another comprising medial and lateral anterior prefrontal cortex. The authors viewed these latter two components as being precursors to the brains "default network." The default network is a system first characterized in adults by a consistent decrease in activity during goal directed tasks compared to baseline (Shulman et al., 1997; Raichle et al., 2001). How this system contributes to brain function in developing and adult populations has received considerable attention in recent years (Greicius et al., 2003; Fox et al., 2005; Fransson, 2005; Fair et al., 2008; Kelly et al., 2009; Supekar et al., 2010), and is still a source of significant debate (Hampson et al., 2006; Burgess et al., 2007; Gilbert et al., 2007; Morcom and Fletcher, 2007).

Since this work, there have been several other studies that have examined correlated spontaneous activity in infants at various stages of development (Lin et al., 2008; Liu et al., 2008; Fransson et al., 2009; Gao et al., 2009; Smyser et al., 2010). The combination of this work suggests that most primary motor and sensory systems while detectable and coherent in these early years, continue to undergo some change as late as 2 years of age (Lin et al., 2008), and likely beyond.

The level of development of other non-primary sensory or motor networks, such as control systems or the default network is, as of now, unclear. There is strong evidence that significant alterations exist for these systems over development; however, studies examining the level of coherence within these networks at early stages of infant development have thus far revealed inconsistent results (Power et al., 2010).

Studies of resting-state functional connectivity have increased significantly in recent years (Uddin et al., 2010; Vogel et al., 2010; Power et al., 2012). One finding that has received significant attention relates to the local and global arrangement of connections between systems. Several authors have now revealed a strong tendency toward a reduction in the number (or proportion) of short-range connections with age and the concomitant increase in number of long-range connections (Fair et al., 2007; Kelly et al., 2009). These observations fit well with suggestions that perceptual and cognitive development involve the simultaneous segregation and integration of information processing streams (Srinivasan, 1999; Johnson, 2001; Luna and Sweeney, 2004; Fair et al., 2006, 2009a; Bunge and Wright, 2007). In fact, functional connectivity changes of this nature over development appear to be strong enough in even a single subject to make fairly accurate predictions 
about the brain maturity of any given individual (Dosenbach et al., 2010). With that said, the robustness of these results has recently come into question as artifact in the form of "micromovements" are likely augmenting findings of this type (Power et al., 2012; Satterthwaite et al., 2012; Van Dijk et al., 2012). While many of the large-scale patterns appear to persist even after correcting for this confound (Van Dijk et al., 2012), it is likely that the distributions, with regard to distance, of connections that get stronger and those that get weaker with age are significantly more overlapping than previously perceived.

One area that has received less attention in the nascent years of developmental rs-fcMRI is cortical-subcortical interactions. Whereas the majority of rs-fcMRI investigations have focused on cortical-cortical changes, subcortical structures and their cortical links also show developmental change during childhood and adolescence. For example, Supekar et al. (2009) showed that subcortical areas are more strongly connected with primary sensory, association, and paralimbic areas in children compared to adults. Fair et al. (2010a) also showed unique developmental corticalsubcortical trajectories with regard to the thalamus (Figure 3). These reports suggest that cortical-subcortical changes, along with cortical-cortical interactions, are likely to contribute to the

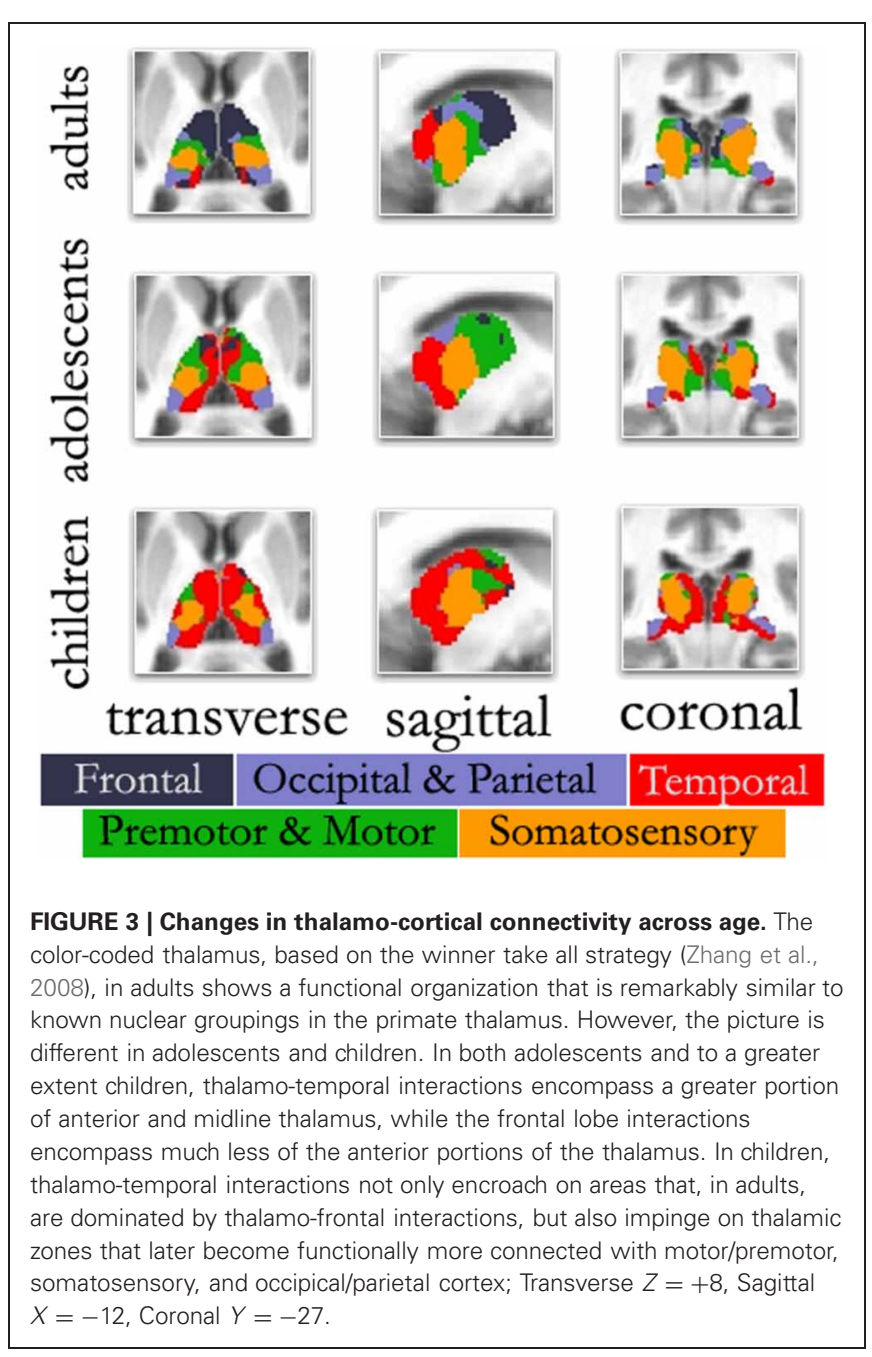

shift from reflexive, stimulus-bound behavior in childhood, to the goal-directed and more flexible functioning that is found in adulthood. An important endeavor with regard to these and other rs-fcMRI findings in future work will be to tie similar theoretical behavioral links with quantitative observations. Some of this work is already underway (e.g., Mills et al., 2012; Stevens et al., 2012).

Importantly, despite the evidence for multiple changes in system organization from childhood through adulthood, at the global level the network structure in childhood remains efficient (at least in school-aged children). For example, in adults, it has been reported on several occasions that the mature brain is organized as a "small world" (Sporns and Zwi, 2004; Sporns and Honey, 2006; Dosenbach et al., 2007). Adult brains show relatively high clustering coefficients, important for segregated information processing, and short path lengths, essential for efficient information transfer (Watts and Strogatz, 1998). Two reports have now revealed that the small world architecture is present in the brains of children as well (Fair et al., 2009b; Supekar et al., 2009). These data suggest that early school age children and young adults both have segregated and efficient cognitive systems that may solve similar information processing problems in divergent ways.

\section{DEVELOPMENT OF THE STRUCTURE-FUNCTION COUPLING}

As noted above, recent connectivity analysis of rs-fcMRI has shown that distinct functional networks become more tightly defined across development (Fair et al., 2007, 2009b). There is now evidence that these functional changes, in part, parallel the white matter maturation.

For example, Fornari et al. (2007) studied the maturation of visual spatial integration and its relation to the myelination of the splenium of the corpus callosum. They applied a combined functional MRI and magnetization transfer imaging paradigm. Fourteen children (age 7-13) were scanned while viewing visual stimuli with or without the requirement for inter-hemispheric integration. They showed that the BOLD response in the lingual gyrus was correlated with the myelination of splenial fibers as measured with magnetization transfer, suggesting that the activation of the extrastriate visual areas, enabling spatial integration, depend on the maturation of long-range cortico-cortical connections.

The maturation of functional systems as described by Fair et al. $(2007,2009 b)$ was the basis of the work by Zielinski et al. (2010). He used a technique called structural covariance of MRI data, which allows the mapping of cortical thickness covariation. Cortical areas that are structurally connected should have a statistical dependence in their thickness according to the authors. There are several hints why cortical areas that are connected (i.e., have synchronous activity) should co-variate in their thickness across a population of subjects. On one hand there is evidence that synchronous neuronal firing promotes synaptogenesis in the involved network (Katz and Shatz, 1996; Bi and Poo, 1999). On the other hand gray matter thickness and volume changes are related to changes in dendritic and synaptic density as well as intra-cortical myelination (for review: Toga et al., 2006). Zielinski used covariance cortical thickness mapping to identify primary sensory and motor networks as well as 
language, social-emotional and other cognitive networks in different age groups. He could show that these networks are present from early childhood through early adulthood and that these structural networks undergo significant maturation along with functional connectivity. High-level networks become increasingly distributed while primary sensory or motor networks expand during adolescence and refocus during early adulthood.

Building on earlier work (Hagmann et al., 2008), Hagmann et al. studied a cohort of subjects ranging from 2 to 18 years and using in combination diffusion MRI and rs-fMRI to create for each subject a brain map of functional and structural connectivity (Hagmann et al., 2010b). In this study the correlation between structural and functional connections was ranging between 0.25 and 0.45 for individual participants, replicating similar results found in adults. Modular organization of structural and functional connectivity is in place in young subjects and does not change (Figure 4A). More intriguingly they observed a clear tendency of increasing structure-function correlation with age $(R=0.74, p<0.005)$ (Figure 4B). At this stage, the authors could not provide a straightforward explanation, but they provided a good overview of the different phenomena likely to play a role (Hagmann et al., 2010b). White matter maturation is known to be a very complicated process where many structural and biochemical changes occur. Axonal diameter increase, packing of bundles takes place, myelin thickness increases and myelin composition changes (Ullen, 2009). Diffusion MRI only provides a crude estimate of these phenomena, and is not sufficient to capture all the subtle microstructural changes influencing neural conduction and information flow (Salami et al., 2003). Not only white matter changes, but also gray matter matures. For example, the particular role of the deep gray nuclei in modulating brain synchrony through topographically segregated loops linking cortex, striatum, and thalamus is maturing and is likely to influence the coupling between structure and function (Haber and Calzavara, 2009; Fair et al., 2010a). Synaptic plasticity and neuro-chemical modifications of the cortex is important. The GABAergic neurotransmission of interneurons is known to critically affect synchrony in the gamma band frequency (Hashimoto et al., 2009; Uhlhaas and Singer, 2010; Gaetz et al., 2011), which in turn may be related to BOLD signals (Niessing et al., 2005) possibly including those seen in resting state fMRI.

\section{REMAINING TECHNICAL CHALLENGES WHEN MAPPING STRUCTURE \\ General tractography challenges}

When inferring connectivity structure by using MRI, it is important to note that MRI is not only of coarse resolution compared to the size of the objects of interest (axons or bundles of axons), but also that diffusion contrast is not a one to one mapping with axonal orientation and structure. Tractography is based on two compulsory assumptions, which are (a) axons are packed
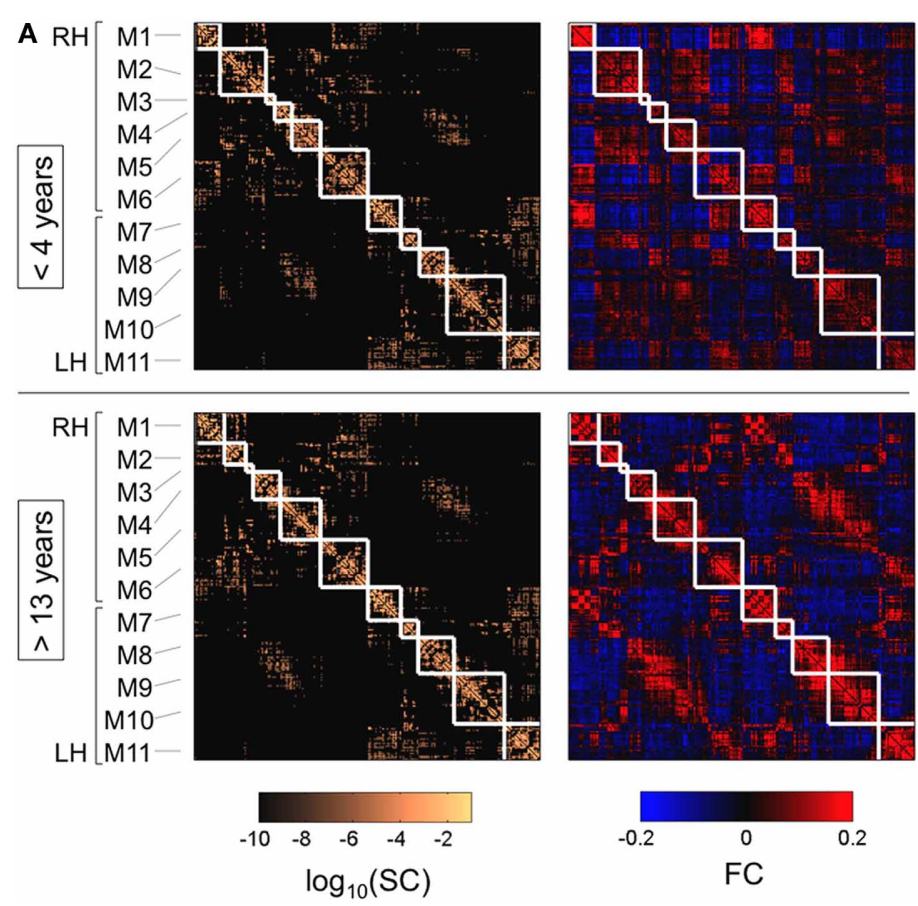

B

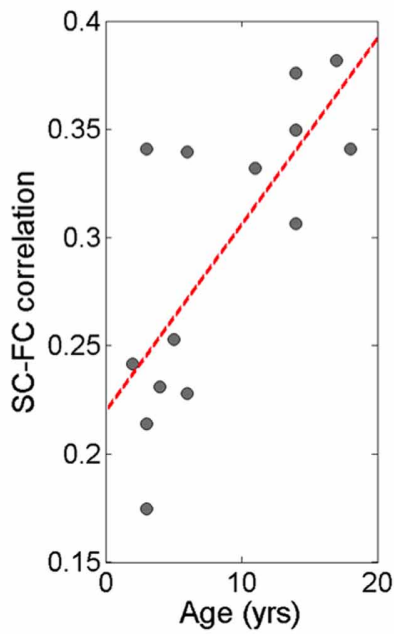

are centered on the following anatomical locations: M1, occipital cortex; M2, parietal cortex; M3, parietal cortex; M4, orbitofrontal cortex; M5, frontal cortex; M6, temporal cortex; M7, occipital cortex; M8, parietal cortex; M9, orbitofrontal cortex; M10, frontal cortex; M11, temporal cortex. (B) Increasing statistical relationship between structural and functional connectivity across age $(R=0.74, p<0.005)$. Adapted from Hagmann et al. (2010b). 
in bundles that have as a whole a smooth and coherent trajectories (b) locally on such bundle a tangent diffusion maximum exists. These two conditions are true for some parts of the brain volume and probably most of the large fiber tracts. There are however also many situations where these two conditions are clearly not respected or not sufficient to solve this ill posed problem. First of all when looking at white matter under the microscope by far not all axons follow the main tract with smooth and coherent trajectories. It is however difficult to evaluate the proportion of such "non-aligned" connections. Second, most voxels do not have one but contain several bundles of coherently aligned fibers. These tracts may locally cross, travel together. Diffusion imaging, independently of the scan quality, technique, and resolution, cannot disentangle fiber trajectories in such situation. The problem is consequently undefined and will result, depending on the tractography technique, in too many false positive or false negative connections. This problem again led to investigation of different algorithms in the HARDI setting (Parker and Alexander, 2005; Perrin et al., 2005; Behrens et al., 2007; Hagmann et al., 2007; Wedeen et al., 2008; Gigandet, 2009). Some groups have tried to relate some complex diffusion PDF shapes to either crossing or kissing fiber profiles (Alexander, 2008). Locally, at the level of a voxel, a small or unmyelinated tract crossing a larger or highly myelinated tract will be obscured in the diffusion measure. This problem is particularly obvious in the centrum semi-ovale of the developing brain, where the corticospinal tract is already well matured and obscures crossing callosal fibers.

\section{Validation work}

Although currently insufficient, some validation work has been done. Using the macaque model (Schmahmann et al., 2007) compared tract reconstructions using post-mortem diffusion MRI tractography with chemical tracing work to demonstrate largely overlapping results. Hagmann et al. (2008) showed at a connectome level reasonable agreement between CoCoMac database (Stephan et al., 2001) and post-mortem diffusion MRI in the macaque. Using the porcine brain (Dyrby et al., 2007) quantitatively and qualitatively assessed the anatomical validity and reproducibility of in vitro multi-fiber probabilistic tractography against two invasive tracers. They demonstrated that probabilistic tractography reliably detected specific pathways and concluded that tractography can be a precise tool in studying anatomical brain connectivity. In the human brain little validation work has been performed since chemical tracers such as DiI take months to diffuse through the extent of an entire axon and cannot track through synapses. Thus characterization of whole brain networks is impossible and data is limited to a few case reports describing limited regions (Clarke et al., 1999; Di Virgilio et al., 1999; Tardif and Clarke, 2001).

\section{Region selection}

Not only accurate mapping of white matter architecture holds many challenges. Also the accurate identification of cortical regions at high resolution is difficult because of the intrinsic variability of the cortical folding and the changing contrast of the developing brain. At low resolution, robust methods exist.
Template based volumetric registration like in (SPM, MNI) or surface based matching like in Freesurfer have shown great results. However some of these methods, such as Freesurfer, do not work in the incompletely myelinated brain. In addition, higher resolution partition of cortical areas is needed, in order to match with cortical localization of function. Smallest Brodmann areas are of the order of a centimeter square, some suggest that there are between 100 and 300 functional areas. Approaches to improve between subject cortical localization have been suggested (also see further discussion below).

\section{Issues proper to development: brain size and anisotropy}

Studying development adds one level of complication because not only the volume of the brain (Mlynarik et al., 2006) but also all MRI contrasts change with age (Barkovich et al., 1988; Huppi et al., 1998; Morriss et al., 1999; Inder and Huppi, 2000; BarneaGoraly et al., 2005; Huppi and Dubois, 2006; Cascio et al., 2007). These changes may be the objective of a study, but if we want to add a biological dimension much care needs to be taken and a profound understanding of developmental biology is essential in order to formulate appropriate hypothesis and make the correct conclusions. In the context of connectivity analysis, this is particularly relevant. Let's take two examples.

In standard tractography, the number of fiber seeds (number of fiber initializations) is proportional to the number of white matter voxels (Hagmann et al., 2007). Furthermore convoluted structures like the corpus callosum and intra-gyral white matter are getting larger with age and related fiber tracts stretch out. Also there are many instances of sharp axonal turns at the boundary with the cortex (Takahashi et al., 2011a). This makes angular thresholds for tractography also a limitation to assessing axonal connectivity. These thresholds are however needed to prevent an overabundance of spurious tracts. Accordingly, with increasing age more small and relatively curved fiber bundles are tracked successfully. This does not mean in any way that a 2 -year-old brain has less axonal connections than a 18 -year-old. In fact, it is the exact opposite. In the maturing brain diffusion anisotropy changes (Huppi et al., 1998; Morriss et al., 1999; Inder and Huppi, 2000; Barnea-Goraly et al., 2005; Huppi and Dubois, 2006; Cascio et al., 2007), which also directly affects tractographic results. The low FA in the unmyelinated white matter hampers traditional tractography approaches in the developing brain.

When modeling developing structural networks, it is essential to associate a contrast that is biologically meaningful to model connection weight. This is however a difficult task since no MRI contrast is totally specific to a biological characteristic. Decreasing diffusivity and increasing FA are typically associated with increasing maturation. However, this interpretation does not take into account the variability in myelin thickness and structure in different pathways and does not take into account the compactness of the axonal bundles. Therefore, mature axonal bundles with thicker myelin and larger axons are likely to have different diffusivity and FA than mature pathways with less myelin and smaller axons. Similarly, tightly packed axonal bundles are likely to have different values than less compact bundles. Other contrasts have also been shown to change with development. T1 relaxation time (Barkovich et al., 1988), MTR (van Buchem et al., 2001) 
and myelin bound water T2 relaxation (Miot-Noirault et al., 1997; Ferrie et al., 1999) are thought to be tightly related to the concentration of myelination and can be of use in such models.

We understand from the above discussion that measuring development of brain connectivity is very challenging and exposed to a high risk of miss-interpratation. Typically one could interpret that the increase in the number of tractographic fibers with age reflects axonal growth of new tracts instead of acknowledging that this is just a bias related to brain volume increase and change in diffusion anisotropy (enabling successful tracking of more fiber components in a voxel). Again, there is no significant change in neuronal number or increase in axonal numbers after birth (Cabungcal et al., 2006; Larsen et al., 2006). Indeed, with the exception of a few brain regions (Menon, 2011), it has become fairly well accepted that most of the neurons we are ever going to possess have migrated and are in place by the time we are born (van den Heuvel et al., 2010; van den Heuvel and Kahn, 2011; Wood et al., 2011). This idea was first proposed by the founder of the neuron doctrine, Santiago Ramon y Cajal, who stated that neurogenesis is an exclusively prenatal event. However, dendritic spine density and synaptogenesis increase rapidly in early childhood and then slowly decrease to adult levels (Glantz et al., 2007; Petanjek et al., 2011). While synaptogenesis continues to occur throughout the lifespan, it occurs at a reduced rate and is accompanied by synaptic pruning resulting in a net loss over time. This includes both micro and macro removal of axons.

Making a developmental study with cross sectional data and not longitudinal data is on its own a challenge because disentangling developmental changes from inter-individual differences is problematic. However collection of longitudinal data over rapidly changing time periods such as the first few months or years of life is more feasible than multiyear studies necessary to resolve different rates of change in adults. Thus by adding this dimension of time enables the use of trajectories to characterize brain development and the possibility to detect differences that may not be evident when development slows later in life.

\section{Strategy to avoid non-plausible conclusions}

It is absolutely essential to work with biologically plausible hypotheses in order to build a model that is in accordance with our current understanding of developmental biology. For example, Hagmann et al. adopted the following strategy when they studied late development (Hagmann et al., 2010b). They modeled structural connection efficacy in two components: connection density and connection maturation. Connection density would take into account the physiologic importance of a pathway (its size) and the mean diffusivity along each tract represent the level of pathway maturation. They made a strong hypothesis by assuming that the pattern of connection densities does not change within age (no change in axonal numbers). Accordingly they have built an average matrix for the connection density by averaging together the connection density matrices of the three oldest subjects (ages 17-18 years) and consequently eliminate inter-individual differences for that component of the model. The older subjects were chosen because their connectivity mapping is believed to be more accurate since maturation is almost complete and late maturing connections like the corpus callosum (see discussion above) are readily identifiable. The resulting average connection density matrix was applied to all subjects.

The maturation component was provided by the apparent diffusion coefficients of neural pathways collected in an individual participant-specific matrix. Based on earlier work, ADC was used as a simple marker of maturation believed influenced by tract compactness and myelination. It provides a rough estimate of maturation. After some normalization maturation was modeled as (1/ADC)-1 with ADC ranging between 0 and 1 . Connection efficacy was then computed as the product between connection density and connection maturity. An important detail is that some pathways were detected in older participants and hence included in the average density, but were not detected in younger subjects, presumably due to varying brain size or their immature myelin status. Rather than excluding these pathways from the analysis, they assumed that they were physically present but inefficacious (not mature). They were assigned an ADC value equivalent to the individual's 95 th percentile. Hence, all structural connection matrices maintained an equal number of pathways, but with individual variations in connection efficacy. With such a construct, the authors were able come up with a reasonable model where only tract maturation changes with age and influences global brain topology.

This example illustrated the mindset that needs to be taken when aiming to study the developing connectome. Obviously when such studies involve a developmental disease and additional level of complexity comes into play and one needs to have a clear mind whether such disease impacts connectional topology or only the physiological weights of the connections. This information needs to be known or clearly hypothetised before creating the model since differentiating these two phenomena from the data is a daunting task. Further work needs also to be done in better understanding the crude relation between MRI contrasts and the maturation processes. It would be wonderful to have an imaging model capable of disentangling changes in axonal diameter, tract density and compactness, and myelination. It would add an additional dimension to our ability to create accurate structural models.

\section{WHEN MAPPING FUNCTION}

\section{ICA versus seed-based correlation analyses}

There are two main approaches for examining correlated activity with rs-fcMRI. One approach is a seed-based correlation method, whereby investigators choose an a-priori region of interest (ROI) and generate a seed correlation map by correlating the time course of the seed with all other voxels in the brain. The other is independent component analysis (ICA). ICA is a datadriven approach and does not necessitate selection of a-priori ROIs. Rather, this method partitions voxels that share variance in their time courses into independent components. Both of these methods have strengths and weaknesses (Fox and Raichle, 2007). Detailing all of the issues here is beyond the scope of this review; however, we will highlight a few particularly relevant to developmental studies. 
While ICA is model free, data driven, and creates reliable connectivity maps, inconsistencies can arise secondary to component selection methods (Fox et al., 2007). In addition, examining component interactions within or between groups (e.g., kids versus adults) is not straightforward as secondary techniques to observe relationships are required. Both techniques may be prone to effects on the BOLD signal due to micro-movements (Power et al., 2012; Van Dijk et al., 2012), an issue that will need to be thoroughly explored in future work, and should be corrected for in all studies. In addition, the seed-based correlation approach has its own specific limitations. For example, the number of potential seed regions one can use to produce a functional connectivity pattern (or map) are only limited by the number of voxels contained in the functional image. As typical imaging protocols generate approximately 100,000 voxels or more, it does not take great imagination to realize the enormous amount of information that can be obtained from any seed-based study. Making sense out of such large amounts of information can be a daunting task.

\section{Graph theory and rs-fcMRI}

One approach that seems capable of overcoming some of the shortcomings from these common rs-fcMRI methodologies is graph theory. Graph theory is a formal method for the study of networks. Most simply, networks are sets of nodes or vertices (e.g., brain regions) joined in pairs by lines or edges (e.g., correlated activity). Many scientifically interesting systems and their functional properties have been described using graph theory, including the development of brain systems noted above. However, even this technique has its pros and cons with regard to studying brain maturation with rs-fcMRI. One limitation is that the derivation of graphs via rs-fcMRI typically requires thresholding of $r$-values. The choice of threshold is, therefore, a critical decision point in the analytical process. For example, choosing an $r$ cut-off approaching 1.0 will generate very sparse graphs (i.e., very few connections), whereas a choice of $r$ close to 0.0 will generate densely connected graphs. Both extremes would limit any potential differences observed between groups or across age. Therefore, it is suggested that any findings using graph theory be replicated across multiple thresholds. Indeed some inconsistencies in the literature may relate to this factor.

\section{Region selection}

Another issue with graph theory (or even rs-fcMRI in general) that may lead to inconsistent findings is region selection. Choosing the correct region set and the correct spatial resolution is not straightforward. Some studies have chosen to examine properties using atlas based anatomical parcellations (Salvador et al., 2005; Achard and Bullmore, 2007; Hagmann et al., 2010b). Others have used functionally defined regions from either previous fMRI or rs-fcMRI studies (Fox et al., 2005; Dosenbach et al., 2007; Fair et al., 2007, 2009b). Choosing the correct spatial resolution is also difficult to determine. Region size has varied in the literature from large ROIs covering entire lobes (Zhang et al., 2008), down to ROIs the size of individual voxels (van den Heuvel et al., 2008). Ideally, regions would be selected based on a known natural scale that partitioned the brain into functionally relevant units.

In Churchland and Sejnowski's famous diagram showing the levels of neuroanatomical organization (Churchland and Sejnowski, 1991), a level labeled "maps." While this scale of functional segregation does not preclude further refinement of the cortex into even more highly divisible units (e.g., ocular dominance or orientation columns within $\mathrm{V} 1$ ), there is strong evidence that there are biological divisions (i.e., functional areas) present in the brain at the level of "maps." For rs-fcMRI studies, due to acquisition resolution, it is (at least as of now) limited to this level of inquiry. Functional areas are morphologically, topologically, and functionally discrete brain areas that are distinct from the more general term "region" or "region of interest" (which may encompass all or part of several functional areas). Four criteria have been proposed for defining cortical areas (Van Essen, 1985; Felleman and Van Essen, 1991; Fuster, 2002; O'Leary and Nakagawa, 2002; Sur and Rubenstein, 2005): Function (functional properties distinct from neighboring cortex), Architectonics (having unique arrangement of cells, myelin density, combinations of chemical markers, etc.), Connections (differing inputs and outputs of neighboring cortex), and Topography (having a topographic map that can be used to define boundaries, for example between primary visual cortex and V2) (FACT). Because true functional areas hold unique combinations of inputs, outputs, and internal structure, each area is thought to make a distinct contribution to information processing (Van Essen, 1985; Felleman and Van Essen, 1991; Fuster, 2002; O'Leary and Nakagawa, 2002; Sur and Rubenstein, 2005; Cohen et al., 2007). As such, examining the natural full set of functional brain areas as nodes for graph theoretical analysis would be ideal. Unfortunately, while work is ongoing (e.g., Cohen et al., 2007; Barnes et al., 2010), identifying a complete collection of functional areas in the human brain is, as of now, out of reach. This is particularly relevant to studies of development because the structural and functional indices we currently used to approximate functional areas change significantly from infancy through adulthood even though we are likely born with an initial broad parcellation of areal architecture (Kostovic et al., 1995). In other words, region sets used to approximate functional areas that are defined by current functional or structural indices are likely to be different depending on at what point they were defined or become refined across the lifespan. As such, how we define our regions could lead to inconsistent findings. It will be important to consider these limitations when conducting and interpreting work using rs-fcMRI.

\section{WHEN STUDYING THE STRUCTURE-FUNCTION COUPLING}

The connectome approach that is now gaining momentum embraces the brain as a large-scale network. This network forms the scaffold for neurological processes and shapes functional dynamics. However, we believe that the brain as it develops contains history in that the coordination and timing of network is likely to have a significant impact on emerging properties. Therefore, it is critical to begin the exploration of network properties with their genesis and acknowledge the additional 
dimension of time that exists throughout life has profound and rapid effects during early brain development. It is equally important not just to utilize imaging strategies developed in adult populations without questioning the assumptions on which the analysis strategies were developed. In particular, it is important to continually strive to understand the cellular and molecular mechanisms driving the imaging changes we interpret as a reflection of "connectivity." A major challenge in developing models of connectivity is to develop a model that transcends scales and domains. Fundamentally cortical microstructure and function give rise to the observed larger scale properties observed with MRI, NIRS, MEG, and EEG. In addition observations in each of the domains need to be linked by a global theoretical framework. With high performance computing and the increasing availability of supercomputers, it is becoming possible to create complex computational models of neural connectivity and function that are informed by known microstructure. Thus we are moving to a time where we not only are able to embrace new areas of mathematics such as graph theory, but also look to computational neurology as a way to bridge across scales and hopefully to infer microscopic properties from our whole brain studies.

\section{OPEN BIOLOGICAL ISSUES WIRING AND MATURATION OF ASSOCIATION FIBERS}

Due to the time intensive nature and high resolution of histological and immunochemical methods, there are still a number of questions remaining about the nature, mechanism and regional variations of developing structural connectivity, especially in the human brain. Cortico-cortical association fibers are particularly difficult to characterize, as are intra-cortical connections. Rodent models are highly valuable to investigate detailed molecular mechanisms involved during development but given their very different brain structure compared to the human they cannot provide the morphological information necessary to fully understand developing human connectivity, in particular complex cortico-cortical connections. Even higher order primate models may not have the same regional variation that is unique to the complex orchestration of normal human development. Probing directly human samples is essential and given the difficulty inherent to histological techniques, in vivo or post-mortem imaging seems to be a technique of choice to address large scale, marco/meso-scopic questions.

\section{VASCULAR MATURATION}

It has long been known that increases in neural activity are followed by an increased blood flow and glucose metabolism, but not a proportional change in oxygen consumption (Raichle and Mintun, 2006). This mismatch between blood flow change and oxygen consumption leads to an increase in the $\mathrm{T} 2 *$-weighted magnetic resonance signal-the basis of fMRI and an effect known as blood oxygen level dependent (BOLD) contrast.

Considering this, one issue that needs attention is how the BOLD response across development changes in relation to developing neuronal activity. For childhood to adulthood studies this has been addressed, in part. While it is conceivable that developmental differences in the hemodynamic response could affect connectivity measures in this age range (D'Esposito et al., 2003), there are a few reports which show that changes observed over development with fMRI are likely not solely the product of changes in hemodynamic response mechanisms over age (Kang et al., 2003; Wenger et al., 2004).

With that said, the relationship of BOLD fluctuations to neuronal activity needs to be further understood, particularly in the early developing brain. $\mathrm{T} 2 *$ changes are driven by changes in deoxyHb volume primarily within the post capillary, venule or venous compartment. The relative size of the different vascular compartments changes significantly over development (Marin-Padilla, 1985; Lauwers et al., 2008). In addition changes in oxyHb are not directly assessed by BOLD fluctuations. Typically at all ages, oxyHb responses are larger than deoxyHb responses (Huppert et al., 2006), therefore the absence of a detectable deoxy $\mathrm{Hb}$ response does not exclude functional vascular responses. Cerebral blood flow changes would be closer to the neuronal activity but the most direct measure of a vascular response would be increases in cerebral metabolic rate of oxygen consumption. Therefore, when studying developing vascular response in the context of ongoing synaptogenesis especially in the context of a complex rapidly changing whole body physiology of the fetus, preterm or neonate, caution is required and attention to known developmental milestones is required. For example the hematocrit nadir that occurs approximately 6 weeks after delivery as fetal hemoglobin transitions to adult hemoglobin can influence cerebral perfusion and impact vascular responses (Roche-Labarbe et al., 2011). In addition, some studies indicate that vascular density is greater in the white matter than in the cortex until around term (Nelson et al., 1991; Miyawaki et al., 1998) and although the leptomeningeal vessels have a muscularis early on, the muscularis of the cortical branches may not develop until 6-9 months of age (Nelson et al., 1991). Such developmental changes may have a significant impact on the interpretation of fetal and preterm BOLD studies and suggest a limitation to local control of vascular supply early in life.

As a result of this increasing demand to better understand microscopic characteristics and to improve our understanding of structural and functional development there is an increasing need to engage the pathologist/neuroscientist. The question of regional variation in maturation and specialization is long known to developmental neurobiologists (Yakovlev and Lecours, 1967; Huttenlocher, 1979; Levitt, 2003; Luo and O'Leary, 2005) and support recent imaging findings. It will be important moving forward to directly link early findings with new imaging work across the multiple levels of inquiry (Churchland and Sejnowski, 1991). Such synergy would lead to a number of new directions of study in the human brain.

\section{CONCLUSION}

The connectome framework for studying human brain development is rapidly increasing in popularity, as it is more and more understood that cognition and behavior arise from distributed network properties. In addition, many mental health 
disorders are neurodevelopmental disorders likely arising from poorly regulated network activity. As a result there is an intense need to develop a framework for studying the developmental trajectory of network properties. A delay in emergence of abnormal network properties may indicate a window of opportunity to intervene with medical or behavioral therapy. In addition, the timing and character of divergence from may provide hints as

\section{REFERENCES}

Achard, S., and Bullmore, E. (2007). Efficiency and cost of economical brain functional networks. PLoS Comput. Biol. 3:e17. doi: 10.1371/ journal.pcbi.0030017

Aeby, A., Liu, Y., De Tiege, X., Denolin, V., David, P., Baleriaux, D., Kavec, M., Metens, T., and Van Bogaert, P. (2009). Maturation of thalamic radiations between 34 and 41 weeks' gestation: a combined voxel-based study and probabilistic tractography with diffusion tensor imaging. AJNR Am. J. Neuroradiol. 30, 1780-1786.

Alexander, D. C. (2008). A general framework for experiment design in diffusion MRI and its application in measuring direct tissue-microstructure features. Magn. Reson. Med. 60, 439-448.

Andrews-Hanna, J. R., Snyder, A. Z., Vincent, J. L., Lustig, C., Head, D., Raichle, M. E., and Buckner, R. L. (2007). Disruption of large-scale brain systems in advanced aging. Neuron 56, 924-935.

Anwander, A., Tittgemeyer, M., von Cramon, D. Y., Friederici, A. D., and Knosche, T. R. (2007). Connectivity-based parcellation of Broca's area. Cereb. Cortex 17, 816-825.

Barkovich, A. J., Kjos, B. O., Jackson, D. E. Jr., and Norman, D. (1988). Normal maturation of the neonatal and infant brain: MR imaging at 1.5 T. Radiology 166, 173-180.

Barnea-Goraly, N., Menon, V., Eckert, M., Tamm, L., Bammer, R., Karchemskiy, A., Dant, C., and Reiss, A. (2005). White matter development during childhood and adolescence: a cross-sectional diffusion tensor imaging study. Cereb. Cortex 15, 1848-1854.

Barnes, K. A., Cohen, A. L., Power, J. D., Nelson, S. M., Dosenbach, Y. B., Miezin, F. M., Petersen, S. E., and Schlaggar, B. L. (2010). Identifying Basal Ganglia divisions in individuals using resting-state functional connectivity MRI. Front. Syst. Neurosci. 4:18. doi: 10.3389/fnsys. 2010.00018

Basser, P. J., Mattiello, J., and LeBihan, D. (1994). MR diffusion tensor spectroscopy and imaging. Biophys. J. 66, 259-267.

Beckmann, M., Johansen-Berg, H., and Rushworth, M. F. (2009). Connectivity-based parcellation of human cingulate cortex and its relation to functional specialization. J. Neurosci. 29, 1175-1190.

Behrens, T. E., Berg, H. J., Jbabdi, S., Rushworth, M. F., and Woolrich, M. W. (2007). Probabilistic diffusion tractography with multiple fibre orientations: what can we gain? Neuroimage 34, 144-155.

Berger, H. (1929). Uber das Electrenkephalogramm des Menschen. Arch. Psychiatr. Nervenkr. 87, 527-570.

Berger, H. (1933). Uber das Electrenkephalogramm des Menschen. Arch. Psychiatr. Nervenkr. 100, 301-320.

Bi, G., and Poo, M. (1999). Distributed synaptic modification in neural networks induced by patterned stimulation. Nature 401, 792-796.

Biswal, B., Yetkin, F. Z., Haughton, Functional connectivity in the motor cortex of resting human brain using echo-planar MRI. Magn. Reson. Med. 34, 537-541.

Bunge, S. A., and Wright, S. B. (2007). Neurodevelopmental changes in working memory and cognitive control. Curr. Opin. Neurobiol. 17, 243-250.

Burgess, P. W., Dumontheil, I., and Gilbert, S. J. (2007). The gateway hypothesis of rostral prefrontal cortex (area 10) function. Trends Cogn. Sci. 11, 290-298.

Butefisch, C. M. (2004). Plasticity in the human cerebral cortex: lessons from the normal brain and from stroke. Neuroscientist 10, 163-173.

Cabungcal, J. H., Nicolas, D., Kraftsik, R., Cuenod, M., Do, K. Q., and Hornung, J. P. (2006). Glutathione deficit during development induces anomalies in the rat anterior cingulate GABAergic neurons: relevance to schizophrenia. Neurobiol. Dis. 22, 624-637.

Cascio, C. J., Gerig, G., and Piven, J. (2007). Diffusion tensor imaging: application to the study of the developing brain. J. Am. Acad. Child Adolesc. Psychiatry 46, 213-223. V. M., and Hyde, J. S. (1995).

to timing or nature of possible secondary "hits," as well as a way to assess success of early interventions prior to the emergence of behavioral phenotypes.

\section{ACKNOWLEDGMENTS}

Patric Hagmann was supported financially by Leenaards Foundation.

Castellanos, F. X., Margulies, D. S., Kelly, C., Uddin, L. Q., Ghaffari, M., Kirsch, A., Shaw, D., Shehzad, Z., Di Martino, A., Biswal, B., SonugaBarke, E. J., Rotrosen, J., Adler, L. A., and Milham, M. P. (2008). Cingulate-precuneus interactions: a new locus of dysfunction in adult attention-deficit/hyperactivity disorder. Biol. Psychiatry 63, 332-337.

Caton, R. (1875). The electric currents of the brain. Br. Med. J. 2, 278.

Changeux, J. P., and Danchin, A. (1976). Selective stabilisation of developing synapses as a mechanism for the specification of neuronal networks. Nature 264, 705-712.

Changeux, J., Heidman, T., Patte, P. (1984). "Learning by selection," in The Biology of Learning, eds P. Marler and H. Terrace (Berlin: Springer-Verlag), 115-133.

Chen, R., Cohen, L. G., and Hallett, M. (2002). Nervous system reorganization following injury. Neuroscience 111, 761-773.

Church, J. A., Fair, D. A., Dosenbach, N. U., Cohen, A. L., Miezin, F. M., Petersen, S. E., and Schlaggar, B. L. (2009). Control networks in paediatric Tourette syndrome show immature and anomalous patterns of functional connectivity. Brain 132, 225-238.

Churchland, P. S., and Sejnowski, T. J. (1991). "Perspectives on cognitive neuroscience," in Perspectives on Cognitive Neuroscience, eds R. G. Lister and H. J. Weingartner (Oxford, UK: Oxford University Press).

Clarke, S., Riahi-Arya, S., Tardif, E., Eskenasy, A. C., and Probst, A. (1999). Thalamic projections of the fusiform gyrus in man. Eur. J. Neurosci. 11, 1835-1838.

Cohen, A. L., Fair, D. A., Dosenbach, N. U., Miezin, F. M., Dierker, D., Van Essen, D. C., Schlaggar, B. L., Petersen, S. E. (2008). Defining functional areas in individual human brains using resting functional connectivity MRI. Neuroimage 41, 45-57.

Conturo, T. E., Lori, N. F., Cull, T. S., Akbudak, E., Snyder, A. Z., Shimony, J. S., McKinstry, R.
C., Burton, H., and Raichle, M. E. (1999). Tracking neuronal fiber pathways in the living human brain. Proc. Natl. Acad. Sci. U.S.A. 96, 10422-10427.

Cordes, D., Haughton, V. M., Arfanakis, K., Carew, J. D., Turski, P. A. Moritz, C. H., Quigley, M. A., and Meyerand, M. E. (2001). Frequencies contributing to functional connectivity in the cerebral cortex in "resting-state" data. AJNR Am. J. Neuroradiol. 22, 1326-1333.

Crowley, J. C., and Katz, L. C. (1999). Development of ocular dominance columns in the absence of retinal input. Nat. Neurosci. 2, 1125-1130.

D’Esposito, M., Deouell, L. Y., and Gazzaley, A. (2003). Alterations in the BOLD fMRI signal with ageing and disease: a challenge for neuroimaging. Nat. Rev. Neurosci. 4, 863-872.

Damoiseaux, J. S., Rombouts, S. A., Barkhof, F., Scheltens, P., Stam, C. J., Smith, S. M., and Beckmann, C. F. (2006). Consistent resting-state networks across healthy subjects. Proc. Natl. Acad. Sci. U.S.A. 103, 13848-13853.

Denk, W., and Horstmann, H. (2004). Serial block-face scanning electron microscopy to reconstruct threedimensional tissue nanostructure. PLoS Biol. 2:e329. doi: 10.1371/journal.pbio.0020329

Di Virgilio, G., Clarke, S., Pizzolato, G., and Schaffner, T. (1999). Cortical regions contributing to the anterior commissure in man. Exp. Brain Res. 124, 1-7.

Dosenbach, N. U., Fair, D. A., Miezin, F. M., Cohen, A. L., Wenger, K. K., Dosenbach, R. A. T., Fox, M. D. Snyder, A. Z., Vincent, J. L., Raichle, M. E., Schlaggar, B. L., and Petersen, S. E. (2007). Distinct brain networks for adaptive and stable task control in humans. Proc. Natl. Acad. Sci. U.S.A. 104, 11073-11078.

Dosenbach, N. U., Nardos, B., Cohen, A. L., Fair, D. A., Power, J. D., Church, J. A., Nelson, S. M., Wig, G. S., Vogel, A. C., Lessov-Schlaggar, C. N., Barnes, K. A., Dubis, J. W., Feczko, E., Coalson, R. S., Pruett, J. R. Jr., Barch, D. M., Petersen, S. E., and Schlaggar, B. 
L. (2010). Prediction of individual brain maturity using fMRI. Science 329, 1358-1361.

Douek, P., Turner, R., Pekar, J., Patronas, N., and Le Bihan, D. (1991). MR color mapping of myelin fiber orientation. J. Comput. Assist. Tomogr. 15, 923-929.

Dubois, J., Hertz-Pannier, L., DehaeneLambertz, G., Cointepas, Y., and Le Bihan, D. (2006). Assessment of the early organization and maturation of infants' cerebral white matter fiber bundles: a feasibility study using quantitative diffusion tensor imaging and tractography. Neuroimage 30, 1121-1132.

Dyrby, T. B., Sogaard, L. V., Parker, G. J., Alexander, D. C., Lind, N. M., Baare, W. F., Hay-Schmidt, A., Eriksen, N., Pakkenberg, B., Paulson, O. B., and Jelsing, J. (2007). Validation of in vitro probabilistic tractography. Neuroimage 37, 1267-1277.

Edelman, G. M., and Finkel, L. H. (1985). "Neuronal group selection in the cerebral cortex," in Dynamic Aspects of Neocortical Function, eds G. M. Edelman, W. E. Gall, and W. M. Cowan (New York, NY: WileyInterscience), 635-695.

Einstein, A. (1956). Investigations on the Theory of the Brownian Movement. New York, NY: Dover Publications.

Eluvathingal, T. J., Hasan, K. M., Kramer, L., Fletcher, J. M., and Ewing-Cobbs, L. (2007). Quantitative diffusion tensor tractography of association and projection fibers in normally developing children and adolescents. Cereb. Cortex 17, 2760-2768.

Eyre, J. A., Miller, S., Clowry, G. J., Conway, E. A., and Watts, C. (2000). Functional corticospinal projections are established prenatally in the human foetus permitting involvement in the development of spinal motor centres. Brain 123(Pt 1), 51-64.

Fair, D. A., Bathula, D., Mills, K. L., Dias, T. G., Blythe, M. S., Zhang, D., Snyder, A. Z., Raichle, M. E., Stevens, A. A., Nigg, J. T., and Nagel, B. J. (2010a). Maturing thalamocortical functional connectivity across development. Front. Syst. Neurosci. 4:10. doi: $10.3389 /$ fnsys. 2010.00010

Fair, D. A., Brown, T. T., Petersen, S. E., and Schlaggar, B. L. (2006). fMRI reveals novel functional neuroanatomy in a child with perinatal stroke. Neurology 67, 2246-2249.

Fair, D. A., Choi, A. H., Dosenbach, Y. B., Coalson, R. S., Miezin, F. M., Petersen, S. E., and Schlaggar, B. L. (2009a). The functional organization of trial-related activity in lexical processing after early left hemispheric brain lesions: an eventrelated fMRI study. Brain Lang. 114, 135-146.

Fair, D. A., Cohen, A. L., Dosenbach, N. U., Church, J. A., Miezin, F. M., Barch, D. M., Raichle, M. E., Petersen, S. E., and Schlaggar, B. L. (2008). The maturing architecture of the brain's default network. Proc. Natl. Acad. Sci. U.S.A. 105, 4028-4032.

Fair, D. A., Cohen, A. L., Power, J. D., Dosenbach, N. U., Church, J. A., Miezin, F. M., Schlaggar, B. L., and Petersen, S. E. (2009b). Functional brain networks develop from a "local to distributed" organization. PLoS Comput. Biol. 5:e1000381. doi: 10.1371/journal.pcbi.1000381

Fair, D. A., Dosenbach, N. U., Church, J. A., Cohen, A. L., Brahmbhatt, S., Miezin, F. M., Barch, D. M., Raichle, M. E., Petersen, S. E., and Schlaggar, B. L. (2007). Development of distinct control networks through segregation and integration. Proc. Natl. Acad. Sci. U.S.A. 104, 13507-13512.

Fair, D. A., Posner, J., Nagel, B. J., Bathula, D., Dias, T. G., Mills, K. L., Blythe, M. S., Giwa, A., Schmitt, C. F., and Nigg, J. T. (2010b). Atypical default network connectivity in youth with attention-deficit/hyperactivity disorder. Biol. Psychiatry 68, 1084-1091.

Felleman, D. J., and Van Essen, D. C. (1991). Distributed hierarchical processing in the primate cerebral cortex. Cereb. Cortex 1, 1-47.

Ferrie, J. C., Barantin, L., Saliba, E., Akoka, S., Tranquart, F., Sirinelli, D., and Pourcelot, L. (1999). MR assessment of the brain maturation during the perinatal period: quantitative T2 MR study in premature newborns. Magn. Reson. Imaging 17, 1275-1288.

Fornari, E., Knyazeva, M. G., Meuli, R., and Maeder, P. (2007). Myelination shapes functional activity in the developing brain. Neuroimage 38, 511-518.

Fox, M. D., Corbetta, M., Snyder, A. Z., Vincent, J. L., and Raichle, M. E. (2006). Spontaneous neuronal activity distinguishes human dorsal and ventral attention systems. Proc. Natl. Acad. Sci. U.S.A. 103, 10046-10051.

Fox, M. D., and Raichle, M. E. (2007). Spontaneous fluctuations in brain activity observed with functional magnetic resonance imaging. Nat. Rev. Neurosci. 8, 700-711.

Fox, M. D., Snyder, A. Z., Vincent, J. L., Corbetta, M., Van Essen, D. C., and Raichle, M. E. (2005). The human brain is intrinsically organized into dynamic, anticorrelated functional networks. Proc. Natl. Acad. Sci. U.S.A. 102, 9673-9678.

Fox, M. D., Snyder, A. Z., Vincent, J. L., and Raichle, M. E. (2007). Intrinsic fluctuations within cortical systems account for intertrial variability in human behavior. Neuron $56,171-184$.

Frackowiak, R. S. J., Friston, K. J., Frith, C. D., Dolan, R. J., and Mazziotta, J. C. (1997). Human Brain Function. San Diego, CA: Academic Press.

Fraguas, D., Gonzalez-Pinto, A., Mico, J. A., Reig, S., Parellada, M., Martinez-Cengotitabengoa, M., Castro-Fornieles, J., Rapado-Castro, M., Baeza, I., Janssen, J., Desco, M., Leza, J. C., and Arango, C. (2012). Decreased glutathione levels predict loss of brain volume in children and adolescents with first-episode psychosis in a two-year longitudina study. Schizophr. Res. 137, 58-65.

Fransson, P. (2005). Spontaneous lowfrequency BOLD signal fluctuations: an fMRI investigation of the resting-state default mode of brain function hypothesis. Hum. Brain Mapp. 26, 15-29.

Fransson, P., Skiold, B., Engstrom, M., Hallberg, B., Mosskin, M., Aden, U., Lagercrantz, H., and Blennow, M. (2009). Spontaneous brain activity in the newborn brain during natural sleep-an fMRI study in infants born at full term. Pediatr. Res. 66, 301-305.

Fransson, P., Skiold, B., Horsch, S., Nordell, A., Blennow, M., Lagercrantz, H., and Aden, U. (2007). Resting-state networks in the infant brain. Proc. Natl. Acad. Sci. U.S.A. 104, 15531-15536.

Friston, K. (2002). Beyond phrenology: what can neuroimaging tell us about distributed circuitry? Annu. Rev. Neurosci. 25, 221-250.

Friston, K. J., Frith, C. D., Liddle, P. F., Frackowiak, R. S. (1993). Functional connectivity: the principal-component analysis of large (PET) data sets. J. Cereb. Blood Flow Metab. 13, 5-14.

Fuster, J. M. (2002). Frontal lobe and cognitive development. J. Neurocytol. 31, 373-385.

Gaetz, W., Edgar, J. C., Wang, D. J., and Roberts, T. P. (2011). Relating MEG measured motor cortical oscillations to resting gamma-aminobutyric acid (GABA) concentration. Neuroimage 55, 616-621.

Gao, W., Zhu, H., Giovanello, K. S., Smith, J. K., Shen, D., Gilmore, J. H., and Lin, W. (2009). Evidence on the emergence of the brain's default network from 2-week-old to 2-year-old healthy pediatric subjects. Proc. Natl. Acad. Sci. U.S.A. 106, 6790-6795.

Ghosh, A., Rho, Y., McIntosh, A. R., Kotter, R., and Jirsa, V. K. (2008). Noise during rest enables the exploration of the brain's dynamic repertoire. PLoS Comput. Biol. 4:e1000196. doi: 10.1371/journal.pcbi.1000196

Gigandet, X. (2009). Global Brain Connectivity Analysis by Diffusion MR Tractography: Algorithms, Validation and Applications. Ph.D. thesis at Signal Processing Laboratory, Vol. 5. Ph.D. Lausanne: Ecole Polytechnique Fédérale de Lausanne (EPFL).

Gilbert, S. J., Dumontheil, I., Simons, J. S., Frith, C. D., and Burgess, P. W. (2007). Comment on "Wandering minds: the default network and stimulus-independent thought". Science 317, 43. author reply 43 .

Glantz, L. A., Gilmore, J. H., Hamer, R. M., Lieberman, J. A., and Jarskog, L. F. (2007). Synaptophysin and postsynaptic density protein 95 in the human prefrontal cortex from mid-gestation into early adulthood. Neuroscience 149, 582-591.

Gonzalez, J. J., Manas, S., De Vera, L., Mendez, L. D., Lopez, S., Garrido, J. M., and Pereda, E. (2011). Assessment of electroencephalographic functional connectivity in term and preterm neonates. Clin. Neurophysiol. 122, 696-702.

Granziera, C., Schmahmann, J. D., Hadjikhani, N., Meyer, H., Meuli, R., Wedeen, V., and Krueger, G. (2009). Diffusion spectrum imaging shows the structural basis of functional cerebellar circuits in the human cerebellum in vivo. PLoS ONE 4:e5101. doi: 10.1371/journal.pone. 0005101

Greicius, M. D., Krasnow, B., Reiss, A. L., and Menon, V. (2003). Functional connectivity in the resting brain: a network analysis of the default mode hypothesis. Proc. Natl. Acad. Sci. U.S.A. 100, 253-258.

Greicius, M. D., Srivastava, G., Reiss, A. L., and Menon, V. (2004). Defaultmode network activity distinguishes Alzheimer's disease from healthy aging: evidence from functional MRI. Proc. Natl. Acad. Sci. U.S.A. 101, 4637-4642.

Greicius, M. D., Supekar, K., Menon, V., and Dougherty, R. F. (2009). Resting-state functional connectivity reflects structural connectivity in the default mode network. Cereb. Cortex 19, 72-78.

Grossberg, S. (1980). How does a brain build a cognitive code? Psychol. Rev. $87,1-51$. 
Haber, S. N., and Calzavara, R. (2009). The cortico-basal ganglia integrative network: the role of the thalamus. Brain Res. Bull. 78, 69-74.

Hagmann, P. (2005). "From diffusion MRI to brain connectomics," in Signal Processing Institute, $\mathrm{PhD}$ thesis, (Lausanne: Ecole Polytechnique Fédérale de Lausanne [EPFL]), 127.

Hagmann, P., Cammoun, L., Gigandet, X., Gerhard, S., Ellen Grant, P., Wedeen, V., Meuli, R., Thiran, J. P., Honey, C. J., and Sporns, O. (2010a). MR connectomics: Principles and challenges. J. Neurosci. Methods 194, 34-45.

Hagmann, P., Cammoun, L., Gigandet, X., Meuli, R., Honey, C. J., Wedeen, V. J., and Sporns, O. (2008). Mapping the structural core of human cerebral cortex. PLoS Biol. 6:e159. doi: 10.1371/journal.pbio.0060159

Hagmann, P., Jonasson, L., Maeder, P., Thiran, J. P., Wedeen, V. J., and Meuli, R. (2006). Understanding diffusion MR imaging techniques: from scalar diffusion-weighted imaging to diffusion tensor imaging and beyond. Radiographics 26(Suppl. 1), S205-S223.

Hagmann, P., Kurant, M., Gigandet, X., Thiran, P., Wedeen, V. J., Meuli, R., and Thiran, J. P. (2007). Mapping human whole-brain structural networks with diffusion MRI. PLoS ONE 2:e597. doi: 10.1371/journal. pone. 0000597

Hagmann, P., Sporns, O., Madan, N., Cammoun, L., Pienaar, R., Wedeen, V. J., Meuli, R., Thiran, J. P., and Grant, P. E. (2010b). White matter maturation reshapes structural connectivity in the late developing human brain. Proc. Natl. Acad. Sci. U.S.A. 107, 19067-19072.

Hampson, M., Driesen, N. R., Skudlarski, P., Gore, J. C., and Constable, R. T. (2006). Brain connectivity related to working memory performance. J. Neurosci. 26, 13338-13343.

Hashimoto, T., Nguyen, Q. L., Rotaru, D., Keenan, T., Arion, D., Beneyto, M., Gonzalez-Burgos, G., and Lewis, D. A. (2009). Protracted developmental trajectories of GABAA receptor alphal and alpha2 subunit expression in primate prefrontal cortex. Biol. Psychiatry 65, 1015-1023.

He, B., and Liu, Z. (2008). Multimodal functional neuroimaging: integrating functional MRI and EEG/MEG. IEEE Rev. Biomed. Eng. 1, 23-40.

Honey, C. J., Kotter, R., Breakspear, M., and Sporns, O. (2007). Network structure of cerebral cortex shapes functional connectivity on multiple time scales. Proc. Natl. Acad. Sci. U.S.A. 104, 10240-10245.

Honey, C. J., Sporns, O., Cammoun, L., Gigandet, X., Thiran, J. P., Meuli, R., and Hagmann, P. (2009). Predicting human resting-state functional connectivity from structural connectivity. Proc. Natl. Acad. Sci. U.S.A. 106, 2035-2040.

Huang, H., Zhang, J., Wakana, S., Zhang, W., Ren, T., Richards, L. J., Yarowsky, P., Donohue, P., Graham, E., van Zijl, P. C., and Mori, S. (2006). White and gray matter development in human fetal, newborn and pediatric brains. Neuroimage 33, 27-38.

Huppert, T. J., Hoge, R. D., Diamond, S. G., Franceschini, M. A., and Boas, D. A. (2006). A temporal comparison of BOLD, ASL, and NIRS hemodynamic responses to motor stimuli in adult humans. Neuroimage 29, 368-382.

Huppi, P. S., and Dubois, J. (2006). Diffusion tensor imaging of brain development. Semin. Fetal Neonatal Med. 11, 489-497.

Huppi, P. S., Maier, S. E., Peled, S., Zientara, G. P., Barnes, P. D., Jolesz, F. A., and Volpe, J. J. (1998). Microstructural development of human newborn cerebral white matter assessed in vivo by diffusion tensor magnetic resonance imaging. Pediatr. Res. 44, 584-590.

Huttenlocher, P. R. (1979). Synaptic density in human frontal cortex developmental changes and effects of aging. Brain Res. 163, 195-205.

Huttenlocher, P. R. (1984). Synapse elimination and plasticity in developing human cerebral cortex. Am. J. Ment. Defic. 88, 488-496.

Inder, T. E., and Huppi, P. S. (2000). In vivo studies of brain development by magnetic resonance techniques. Ment. Retard. Dev. Disabil. Res. Rev. 6, 59-67.

Innocenti, G. M. (1995). Exuberant development of connections, and its possible permissive role in cortical evolution. Trends Neurosci. 18, 397-402.

Iturria-Medina, Y., Sotero, R. C., Canales-Rodriguez, E. J., AlemanGomez, Y., and Melie-Garcia, L. (2008). Studying the human brain anatomical network via diffusionweighted MRI and Graph Theory. Neuroimage 40, 1064-1076.

Izhikevich, E. M., and Edelman, G. M. (2008). Large-scale model of mammalian thalamocortical systems. Proc. Natl. Acad. Sci. U.S.A. 105, 3593-3598.

Jeong, J. (2004). EEG dynamics in patients with Alzheimer's disease. Clin. Neurophysiol. 115, 1490-1505.
Johansen-Berg, H., Behrens, T. E., Robson, M. D., Drobnjak, I., Rushworth, M. F., Brady, J. M., Smith, S. M., Higham, D. J., and Matthews, P. M. (2004). Changes in connectivity profiles define functionally distinct regions in human medial frontal cortex. Proc. Natl. Acad. Sci. U.S.A. 101, 13335-13340.

Johansen-Berg, H., and Rushworth, M. F. (2009). Using diffusion imaging to study human connectional anatomy. Annu Rev. Neurosci. 32, 75-94.

Johnson, M. H. (1997). Developmental Cognitive Neuroscience. Oxford, UK: Blackwells.

Johnson, M. H. (2001). Functional brain development in humans. Nat. Rev. Neurosci. 2, 475-483.

Just, M. A., Cherkassky, V. L., Keller, T. A., Kana, R. K., and Minshew, N. J. (2007). Functional and anatomical cortical underconnectivity in autism: evidence from an FMRI study of an executive function task and corpus callosum morphometry. Cereb. Cortex 17, 951-961.

Kalinovsky, A., Boukhtouche, F., Blazeski, R., Bornmann, C., Suzuki, N., Mason, C. A., and Scheiffele, P. (2011). Development of axon-target specificity of ponto-cerebellar afferents. PLoS Biol. 9:e1001013. doi: 10.1371/journal.pbio.1001013

Kang, H. C., Burgund, E. D., Lugar, H. M., Petersen, S. E., and Schlaggar, B. L. (2003). Comparison of functional activation foci in children and adults using a common stereotactic space. Neuroimage 19, 16-28.

Kasprian, G., Brugger, P. C., Weber, M., Krssak, M., Krampl, E., Herold, C., and Prayer, D. (2008). In utero tractography of fetal white matter development. Neuroimage 43, 213-224.

Katz, L. C., and Crowley, J. C. (2002). Development of cortical circuits: lessons from ocular dominance columns. Nat. Rev. Neurosci. 3, 34-42.

Katz, L. C., and Shatz, C. J. (1996). Synaptic activity and the construction of cortical circuits. Science 274, 1133-1138.

Kelly, A. M., Di Martino, A., Uddin, L. Q., Shehzad, Z., Gee, D. G., Reiss, P. T., Margulies, D. S., Castellanos, F. X., and Milham, M. P. (2009). Development of anterior cingulate functional connectivity from late childhood to early adulthood. Cereb. Cortex 19, 640-657.

Kiviniemi, V., Jauhiainen, J., Tervonen, O., Pakkko, E., Oikarinen, J., Vainionpaa, V., Rantala, H., and Biswal, B. (2000). Slow vasomotor fluctuation in fMRI of anesthetized child brain. Magn. Reson. Med. 44, 373-378.

Knock, S. A., McIntosh, A. R., Sporns, O., Kötter, R., Hagmann, P., and Jirsa, V. K. (2009). The effects of physiologically plausible connectivity structure on local and global dynamics in large scale brain models. J. Neurosci. Methods 183, 86-94.

Koch, M. A., Norris, D. G., and Hund-Georgiadis, M. (2002). An investigation of functional and anatomical connectivity using magnetic resonance imaging. Neuroimage 16, 241-250.

Kostovic, I., Judas, M., Petanjek, Z., and Simic, G. (1995). Ontogenesis of goal-directed behavior: anatomofunctional considerations. Int J. Psychophysiol. 19, 85-102.

Larsen, C. C., Bonde Larsen, K., Bogdanovic, N., Laursen, H., Graem, N., Samuelsen, G. B., and Pakkenberg, B. (2006). Total number of cells in the human newborn telencephalic wall. Neuroscience 139, 999-1003.

Lauwers, F., Cassot, F., Lauwers-Cances, V., Puwanarajah, P., and Duvernoy, H. (2008). Morphometry of the human cerebral cortex microcirculation: general characteristics and space-related profiles. Neuroimage 39, 936-948.

Le Bihan, D. (1995). Molecular diffusion, tissue microdynamics and microstructure. NMR Biomed. 8, 375-386.

Lee, L., Harrison, L. M., and Mechelli, A. (2003). A report of the functional connectivity workshop, Dusseldorf 2002. Neuroimage 19, 457-465.

Levitt, P. (2003). Structural and functional maturation of the developing primate brain. J. Pediatr. 143, S35-S45.

Lichtman, J. W., Livet, J., and Sanes, J. R. (2008). A technicolour approach to the connectome. Nat. Rev Neurosci. 9, 417-422.

Lin, W., Zhu, Q., Gao, W., Chen, Y., Toh, C. H., Styner, M., Gerig, G., Smith, J. K., Biswal, B., and Gilmore, J. H. (2008). Functional connectivity MR imaging reveals cortical functional connectivity in the developing brain. AJNR Am. J. Neuroradiol. 29, 1883-1889.

Liu, W. C., Flax, J. F., Guise, K. G., Sukul, V., and Benasich, A. A. (2008). Functional connectivity of the sensorimotor area in naturally sleeping infants. Brain Res. 1223, 42-49.

Liu, Y., Baleriaux, D., Kavec, M., Metens, T., Absil, J., Denolin, V., Pardou, A., Avni, F., Van Bogaert, P., and Aeby, A. (2010). Structural asymmetries in motor and language 
networks in a population of healthy preterm neonates at term equivalent age: a diffusion tensor imaging and probabilistic tractography study. Neuroimage 51, 783-788.

Logothetis, N. K., and Wandell, B. A. (2004). Interpreting the BOLD signal. Annu. Rev. Physiol. 66, 735-769.

Lotto, R. B., Aitkenhead, A., and Price, D. J. (1999). Effects of the thalamus on the development of cerebral cortical efferents in vitro. J. Neurobiol. 39, 186-196.

Lowe, M. J., Mock, B. J., and Sorenson, J. A. (1998). Functional connectivity in single and multislice echoplanar imaging using resting-state fluctuations. Neuroimage 7, 119-132.

Lu, H., Zuo, Y., Gu, H., Waltz, J. A., Zhan, W., Scholl, C. A., Rea, W., Yang, Y., and Stein, E. A. (2007). Synchronized delta oscillations correlate with the resting-state functional MRI signal. Proc. Natl. Acad. Sci. U.S.A. 104, 18265-18269.

Luna, B., and Sweeney, J. A. (2004). The emergence of collaborative brain function: FMRI studies of the development of response inhibition. Ann. N.Y. Acad. Sci. 1021, 296-309.

Luo, L., and O'Leary, D. D. (2005). Axon retraction and degeneration in development and disease. Annu. Rev. Neurosci. 28, 127-156.

Marin-Padilla, M. (1985). Early vascularization of the embryonic cerebral cortex: Golgi and electron microscopic studies. J. Comp. Neurol. 241, 237-249.

Menon, V. (2011). Large-scale brain networks and psychopathology: a unifying triple network model. Trends Cogn. Sci. 15, 483-506.

Micheva, K. D., and Smith, S. J. (2007). Array tomography: a new tool for imaging the molecular architecture and ultrastructure of neural circuits. Neuron 55, 25-36.

Mills, K. L., Bathula, D., Dias, T. G., Iyer, S. P., Fenesy, M. C., Musser, E. D., Stevens, C. A., Thurlow, B. L., Carpenter, S. D., Nagel, B. J., Nigg, J. T., and Fair, D. A. (2012). Altered cortico-striatal-thalamic connectivity in relation to spatial working memory capacity in children with ADHD. Front. Psychiatry 3:2. doi: 10.3389/fpsyt.2012.00002

Miot-Noirault, E., Barantin, L., Akoka, S., and Le Pape, A. (1997). T2 relaxation time as a marker of brain myelination: experimental MR study in two neonatal animal models. J. Neurosci. Methods 72, 5-14.

Miyawaki, T., Matsui, K., and Takashima, S. (1998). Developmental characteristics of vessel density in the human fetal and infant brains. Early Hum. Dev. 53, 65-72.

Mlynarik, V., Gambarota, G., Frenkel, H., and Gruetter, R. (2006). Localized short-echo-time proton MR spectroscopy with full signalintensity acquisition. Magn. Reson. Med. 56, 965-970.

Montague, P. R., Gally, J. A., and Edelman, G. M. (1991). Spatial signaling in the development and function of neural connections. Cereb. Cortex 1, 199-220.

Morcom, A. M., and Fletcher, P. C. (2007). Does the brain have a baseline? Why we should be resisting a rest. Neuroimage 37, 1073-1082.

Mori, S., Crain, B. J., Chacko, V. P., and van Zijl, P. C. (1999). Threedimensional tracking of axonal projections in the brain by magnetic resonance imaging. Ann. Neurol. 45, 265-269.

Morriss, M. C., Zimmerman, R. A., Bilaniuk, L. T., Hunter, J. V., and Haselgrove, J. C. (1999). Changes in brain water diffusion during childhood. Neuroradiology 41, 929-934.

Moseley, M. E., Kucharczyk, J., Mintorovitch, J., Cohen, Y., Kurhanewicz, J., Derugin, N., Asgari, H., and Norman, D. (1990). Diffusion-weighted MR imaging of acute stroke: correlation with T2-weighted and magnetic susceptibility-enhanced MR imaging in cats. AJNR Am. J. Neuroradiol. 11, 423-429.

Mukherjee, P., and McKinstry, R. C. (2006). Diffusion tensor imaging and tractography of human brain development. Neuroimaging Clin. N. Am. 16, 19-43, vii.

Muller, F., and O'Rahilly, R. (2006). The amygdaloid complex and the medial and lateral ventricular eminences in staged human embryos. J. Anat. 208, 547-564.

Nelson, M. D. Jr., Gonzalez-Gomez, I., and Gilles, F. H. (1991). Dyke Award. The search for human telencephalic ventriculofugal arteries. AJNR Am. J. Neuroradiol. 12, 215-222.

Niessing, J., Ebisch, B., Schmidt, K. E., Niessing, M., Singer, W., and Galuske, R. A. (2005). Hemodynamic signals correlate tightly with synchronized gamma oscillations. Science 309, 948-951.

Nucifora, P. G., Verma, R., Lee, S. K., and Melhem, E. R. (2007). Diffusion-tensor MR imaging and tractography: exploring brain microstructure and connectivity. Radiology 245, 367-384.

O'Leary, D. D., and Nakagawa, Y. (2002). Patterning centers, regulatory genes and extrinsic mechanisms controlling arealization of the neocortex. Curr. Opin. Neurobiol. 12, 14-25.

Parker, G. J., and Alexander, D. C. (2005). Probabilistic anatomical connectivity derived from the microscopic persistent angular structure of cerebral tissue. Philos. Trans. R. Soc. Lond. B Biol. Sci. 360, 893-902.

Perrin, M., Poupon, C., Cointepas, Y., Rieul, B., Golestani, N., Pallier, C., Riviere, D., Constantinesco, A., Le Bihan, D., and Mangin, J. F. (2005). Fiber tracking in q-ball fields using regularized particle trajectories. Inf. Process. Med. Imaging 19, 52-63.

Petanjek, Z., Judas, M., Simic, G., Rasin, M. R., Uylings, H. B., Rakic, P., and Kostovic, I. (2011). Extraordinary neoteny of synaptic spines in the human prefrontal cortex. Proc. Natl. Acad. Sci. U. S. A. 108, 13281-13286.

Power, J. D., Barnes, K. A., Snyder, A. Z., Schlaggar, B. L., and Petersen, S. E. (2012). Spurious but systematic correlations in functional connectivity MRI networks arise from subject motion. Neuroimage 59, 2142-2154.

Power, J. D., Fair, D. A., Schlaggar, B. L., and Petersen, S. E. (2010). The development of human functional brain networks. Neuron 67, 735-748.

Price, D. J., Kennedy, H., Dehay, C., Zhou, L., Mercier, M., Jossin, Y., Goffinet, A. M., Tissir, F., Blakey, D., and Molnar, Z. (2006). The development of cortical connections. Eur. J. Neurosci. 23, 910-920.

Raichle, M. E., MacLeod, A. M., Snyder, A. Z., Powers, W. J., Gusnard, D. A., and Shulman, G. L. (2001). A default mode of brain function. Proc. Natl. Acad. Sci. U.S.A. 98, 676-682.

Raichle, M. E., and Mintun, M. A. (2006). Brain work and brain imaging. Annu. Rev. Neurosci. 29, 449-476.

Redcay, E., Kennedy, D. P., and Courchesne, E. (2007). fMRI during natural sleep as a method to study brain function during early childhood. Neuroimage 38, 696-707.

Roche-Labarbe, N., Carp, S. A., Surova, A., Patel, M., Boas, D. A., Grant, P. E., and Franceschini, M. A. (2011). Noninvasive optical measures of $\mathrm{CBV}$, StO(2), CBF index, and $\mathrm{rCMRO}(2)$ in human premature neonates' brains in the first six weeks of life. Hum. Brain Mapp. 31, 341-352.

Sahin, N. T., Pinker, S., Cash, S. S., Schomer, D., and Halgren, E.
(2009). Sequential processing of lexical, grammatical, and phonological information within Broca's area. Science 326, 445-449.

Saksena, S., Husain, N., Das, V., Pradhan, M., Trivedi, R., Srivastava, S., Malik, G. K., Rathore, R. K., Sarma, M., Pandey, C. M., and Gupta, R. K. (2008a). Diffusion tensor imaging in the developing human cerebellum with histologic correlation. Int. J. Dev. Neurosci. 26, 705-711.

Saksena, S., Husain, N., Malik, G. K., Trivedi, R., Sarma, M., Rathore, R. S., Pandey, C. M., and Gupta, R. K. (2008b). Comparative evaluation of the cerebral and cerebellar white matter development in pediatric age group using quantitative diffusion tensor imaging. Cerebellum 7, 392-400.

Salami, M., Itami, C., Tsumoto, T., and Kimura, F. (2003). Change of conduction velocity by regional myelination yields constant latency irrespective of distance between thalamus and cortex. Proc. Natl. Acad. Sci. U.S.A. 100, 6174-6179.

Salvador, R., Suckling, J., Coleman, M. R., Pickard, J. D., Menon, D., and Bullmore, E. (2005). Neurophysiological architecture of functional magnetic resonance images of human brain. Cereb. Cortex 15, 1332-1342.

Satterthwaite, T. D., Wolf, D. H., Loughead, J., Ruparel, K., Elliott, M. A., Hakonarson, H., Gur, R. C. and Gur, R. E. (2012). Impact of inscanner head motion on multiple measures of functional connectivity: relevance for studies of neurodevelopment in youth. Neuroimage 60, 623-632.

Schmahmann, J. D., and Pandya, D. N. (2006). Fiber Pathways of the Brain. New York, NY: Oxford University Press.

Schmahmann, J. D., Pandya, D. N., Wang, R., Dai, G., D’Arceuil, H. E., de Crespigny, A. J., and Wedeen, V. J. (2007). Association fibre pathways of the brain: parallel observations from diffusion spectrum imaging and autoradiography. Brain 130, 630-653.

Scholvinck, M. L., Maier, A., Ye, F Q., Duyn, J. H., and Leopold, D. A. (2010). Neural basis of global resting-state fMRI activity. Proc. Natl. Acad. Sci. U.S.A. 107 10238-10243.

Shehzad, Z., Kelly, A. M., Reiss, P. T., Gee, D. G., Gotimer, K., Uddin, L. Q., Lee, S. H., Margulies, D. S., Roy, A. K., Biswal, B. B., Petkova, E., Castellanos, F. X., and Milham, M. P. (2009). The resting brain: 
unconstrained yet reliable. Cereb. Cortex 19, 2209-2229.

Shulman, G. L., Fiez, J. A., Corbetta, M., Buckner, R. L., Miezin, F. M., Raichle, M. E., and Petersen, S. E. (1997). Common blood flow changes across visual tasks: II. Decreases in cerebral cortex. J. Cogn. Neurosci. 9, 648-663.

Smith, J. F., Pillai, A., Chen, K., and Horwitz, B. (2011). Effective connectivity modeling for fMRI: six issues and possible solutions using linear dynamic systems. Front. Syst. Neurosci. 5:104. doi: 10.3389/fnsys.2011.00104

Smyser, C. D., Inder, T. E., Shimony, J. S., Hill, J. E., Degnan, A. J., Snyder, A. Z., and Neil, J. J. (2010). Longitudinal analysis of neural network development in preterm infants. Cereb. Cortex 20, 2852-2862.

Sporns, O., and Honey, C. J. (2006). Small worlds inside big brains. Proc. Natl. Acad. Sci. U.S.A. 103, 19219-19220.

Sporns, O., Tononi, G., and Kotter, R. (2005). The human connectome: a structural description of the human brain. PLoS Comput. Biol. 1:e42:doi: 10.1371/journal.pcbi.0010042

Sporns, O., and Zwi, J. D. (2004). The small world of the cerebral cortex. Neuroinformatics 2, 145-162.

Srinivasan, R. (1999). Spatial structure of the human alpha rhythm: global correlation in adults and local correlation in children. Clin. Neurophysiol. 110, 1351-1362.

Stam, C. J. (2010). Use of magnetoencephalography (MEG) to study functional brain networks in neurodegenerative disorders. J. Neurol. Sci. 289, 128-134.

Stevens, A. A., Tappon, S. C., Garg, A., and Fair, D. A. (2012). Functional brain network modularity captures inter- and intra-individual variation in working memory capacity. PLoS ONE 7:e30468. doi: 10.1371/journal.pone.0030468

Stephan, K. E. (2004). On the role of general system theory for functional neuroimaging. J. Anat. 205, 443-470.

Stephan, K. E., Kamper, L., Bozkurt, A., Burns, G. A., Young, M. P., and Kotter, R. (2001). Advanced database methodology for the Collation of Connectivity data on the Macaque brain (CoCoMac). Philos. Trans. R. Soc. Lond. B Biol. Sci. 356, 1159-1186.

Supekar, K., Musen, M., and Menon, V. (2009). Development of largescale functional brain networks in children. PLoS Biol. 7:e1000157:doi: 10.1371/journal.pbio.1000157
Supekar, K., Uddin, L. Q., Prater, K., Amin, H., Greicius, M. D., and Menon, V. (2010). Development of functional and structural connectivity within the default mode network in young children. Neuroimage 52, 290-301.

Sur, M., and Leamey, C. A. (2001). Development and plasticity of cortical areas and networks. Nat. Rev. Neurosci. 2, 251-262.

Sur, M., and Rubenstein, J. L. (2005). Patterning and plasticity of the cerebral cortex. Science 310, 805-810.

Swartz, B. E., and Goldensohn, E. S. (1998). Timeline of the history of EEG and associated fields. Electroencephalogr. Clin. Neurophysiol. 106, 173-176.

Takahashi, E., Dai, G., Rosen, G. D., Wang, R., Ohki, K., Folkerth, R. D., Galaburda, A. M., Wedeen, V. J., and Ellen Grant, P. (2011a). Developing neocortex organization and connectivity in cats revealed by direct correlation of diffusion tractography and histology. Cereb. Cortex 21, 200-211.

Takahashi, E., Folkerth, R., Galaburda, A., and Grant, P. (2011b). Radial and Tangential Migrational Pathways Revealed by Diffusion Tractography. Montreal, QC: ISMRM.

Takahashi, E., Folkerth, R. D., Galaburda, A. M., and Grant, P. E. (2012). Emerging cerebral connectivity in the human fetal brain: an MR tractography study. Cereb. Cortex 22, 455-464.

Tardif, E., and Clarke, S. (2001). Intrinsic connectivity of human auditory areas: a tracing study with DiI. Eur. J. Neurosci. 13, 1045-1050.

Teipel, S. J., Pogarell, O., Meindl, T., Dietrich, O., Sydykova, D., Hunklinger, U., Georgii, B., Mulert, C., Reiser, M. F., Moller, H. J., and Hampel, H. (2009). Regional networks underlying interhemispheric connectivity: an EEG and DTI study in healthy ageing and amnestic mild cognitive impairment. Hum. Brain Mapp. 30, 2098-2119.

Toga, A. W., Thompson, P. M., and Sowell, E. R. (2006). Mapping brain maturation. Trends Neurosci. 29, 148-159.

Tononi, G., and Edelman, G. M. (2000). Schizophrenia and the mechanisms of conscious integration. Brain Res. Brain Res. Rev. 31, 391-400.

Uddin, L. Q., Supekar, K., and Menon, V. (2010). Typical and atypical development of functional human brain networks: insights from resting-state fMRI. Front. Syst. Neurosci. 4:21. doi: 10.3389/fnsys. 2010.00021
Uhlhaas, P. J., and Singer, W. (2010). Abnormal neural oscillations and synchrony in schizophrenia. Nat. Rev. 11, 100-113.

Ullen, F. (2009). Is activity regulation of late myelination a plastic mechanism in the human nervous system? Neuron Glia Biol. 5, 29-34.

van Buchem, M. A., Steens, S. C., Vrooman, H. A., Zwinderman, A. H., McGowan, J. C., Rassek, M., and Engelbrecht, V. (2001). Global estimation of myelination in the developing brain on the basis of magnetization transfer imaging: a preliminary study. AJNR Am. J. Neuroradiol. 22, 762-766.

van den Heuvel, M., Mandl, R., Luigjes, J., and Hulshoff Pol, H. (2008). Microstructural organization of the cingulum tract and the level of default mode functional connectivity. J. Neurosci. 28, 10844-10851.

van den Heuvel, M. P., and Kahn, R. S. (2011). Abnormal brain wiring as a pathogenetic mechanism in schizophrenia. Biol. Psychiatry 70, 1107-1108.

van den Heuvel, M. P., Mandl, R. C., Stam, C. J., Kahn, R. S., and Hulshoff Pol, H. E. (2010). Aberrant frontal and temporal complex network structure in schizophrenia: a graph theoretical analysis. J. Neurosci. 30, 15915-15926.

Van Dijk, K. R., Sabuncu, M. R., and Buckner, R. L. (2012). The influence of head motion on intrinsic functional connectivity MRI. Neuroimage 59, 431-438.

Van Essen, D. C. (1985). "Functional organization of primate visual cortex," in Cerebral Cortex, eds A. Peters and E. G. Jones (New York, NY: Plenum Press), 259-329.

Varela, F., Lachaux, J. P., Rodriguez, E., and Martinerie, J. (2001). The brainweb: phase synchronization and large-scale integration. Nat. Rev. 2, 229-239.

Vasung, L., Huang, H., JovanovMilosevic, N., Pletikos, M., Mori, S., and Kostovic, I. (2011a). Development of axonal pathways in the human fetal fronto-limbic brain: histochemical characterization and diffusion tensor imaging. J. Anat. 217, 400-417.

Vasung, L., Jovanov-Milosevic, N., Pletikos, M., Mori, S., Judas, M., and Kostovic, I. (2011b). Prominent periventricular fiber system related to ganglionic eminence and striatum in the human fetal cerebrum. Brain Struct. Funct. 215, 237-253.

Vincent, J. L., Patel, G. H., Fox, M. D., Snyder, A. Z., Baker, J. T., Van Essen, D. C., Zempel, J. M., Snyder, L. H., Corbetta, M., and Raichle, M.
E. (2007). Intrinsic functional architecture in the anaesthetized monkey brain. Nature 447, 83-86.

Vogel, A. C., Power, J. D., Petersen, S. E., and Schlaggar, B. L. (2010). Development of the brain's functional network architecture. Neuropsychol. Rev. 20, 362-375.

von der Malsburg, C. (1995). "Selforganization in the brain," in The Handbook of Brain Theory and Neural Networks, ed M. Arbib (Cambridge, MA: MIT Press).

Watts, D. J., and Strogatz, S. H. (1998). Collective dynamics of 'small-world' networks. Nature 393, 440-442.

Wedeen, V. (1996). "Diffusion aniostropy and white matter tracts," in Proceedings of the Second International Conference on Functional Mapping of the Human Brain, Vol. 2 (Boston, MA), S146.

Wedeen, V. J., Rosene, D. L., Wang, R., Dai, G., Mortazavi, F., Hagmann, P., Kaas, J. H., and Tseng, W. Y. (2012). The geometric structure of the brain fiber pathways. Science 335, 1628-1634.

Wedeen, V. J., Wang, R. P., Schmahmann, J. D., Benner, T., Tseng, W. Y., Dai, G., Pandya, D. N., Hagmann, P., D'Arceuil, H. and de Crespigny, A. J. (2008). Diffusion spectrum magnetic resonance imaging (DSI) tractography of crossing fibers. Neuroimage 41, 1267-1277.

Wenger, K. K., Visscher, K. M., Miezin, F. M., Petersen, S. E., and Schlaggar, B. L. (2004). Comparison of sustained and transient activity in children and adults using a mixed blocked/event-related fMRI design. Neuroimage 22, 975-985.

Werner, G. (2007). Brain dynamics across levels of organization. J. Physiol. Paris 101, 273-279.

Wood, S. J., Yung, A. R., McGorry, P. D., and Pantelis, C. (2011). Neuroimaging and treatment evidence for clinical staging in psychotic disorders: from the at-risk mental state to chronic schizophrenia. Biol. Psychiatry 70, 619-625.

Xiang, H. D., Fonteijn, H. M., Norris, D. G., and Hagoort, P. (2010). Topographical functional connectivity pattern in the perisylvian language networks. Cereb. Cortex 20, 549-560.

Yakovlev, P., and Lecours, A. (1967) "The myelogenetic cycles of regional maturation of the brain," in Regional Development of the Brain in Early Life, ed A. Minkowski (Oxford: Blackewell Scientific), 3-70.

Zhang, D., Snyder, A. Z., Fox, M. D., Sansbury, M. W., Shimony, 
J. S., and Raichle, M. E. (2008). Intrinsic functional relations between human cerebral cortex and thalamus. J. Neurophysiol. 100, 1740-1748.

Zielinski, B. A., Gennatas, E. D., Zhou, J., and Seeley, W. W. (2010). Network-level structural covariance in the developing brain.
Proc. Natl. Acad. Sci. U.S.A. 107, Received: 17 April 2011; accepted: 08 18191-18196.

Conflict of Interest Statement: The authors declare that the research was conducted in the absence of any commercial or financial relationships that could be construed as a potential conflict of interest. May 2012; published online: 13 June 2012.

Citation: Hagmann $P$, Grant $P E$ and Fair DA (2012) MR connectomics: a conceptual framework for studying the developing brain. Front. Syst. Neurosci. 6:43. doi: 10.3389/fnsys. 2012.00043
Copyright (C) 2012 Hagmann, Grant and Fair. This is an open-access article distributed under the terms of the Creative Commons Attribution Non Commercial License, which permits non-commercial use, distribution, and reproduction in other forums, provided the original authors and source are credited. 